\title{
CFD Analysis in Advance of the NASA Juncture Flow Experiment
}

\author{
H. C. Lee, Science Technology Corporation, Moffett Field, CA 94035 \\ T. H. Pulliam, NASA Ames Research Center, Moffett Field, CA 94035 \\ D. H. Neuhart $\ddagger^{\ddagger}$ M. A. Kegerise ${ }^{\S}$ \\ NASA Langley Research Center, Hampton, VA 23681-2199
}

\begin{abstract}
NASA through its Transformational Tools and Technologies Project (TTT) under the Advanced Air Vehicle Program, is supporting a substantial effort to investigate the formation and origin of separation bubbles found on wing-body juncture zones. The flow behavior in these regions is highly complex, difficult to measure experimentally, and challenging to model numerically. Multiple wing configurations were designed and evaluated using Computational Fluid Dynamics (CFD), and a series of wind tunnel risk reduction tests were performed to further down-select the candidates for the final experiment. This paper documents the CFD analysis done in conjunction with the 6 percent scale risk reduction experiment performed in NASA Langley's 14- by 22-Foot Subsonic Tunnel. The combined CFD and wind tunnel results ultimately helped the Juncture Flow committee select the the wing configurations for the final experiment.
\end{abstract}

\section{Introduction}

Juncture flows are very difficult to predict, even with the current state-of-the-art CFD methods. In AIAA Drag Prediction Workshop 3 (DPW-3), which used the DLR-F6 wing-body, participants predicted a very wide range of side-of-body separations. ${ }^{1,2}$ The same issue arose for the Common Research Model (CRM) in DPW-4 and DPW-5. ${ }^{3}$ The introduction of the quadratic constitutive relation (QCR) terms for the Reynolds-averaged Navier-Stokes equations (RANS) by Spalart [4] did make the predicted separation bubble sizes over various CFD codes more homogeneous, but the solutions are still over-predicting bubble size when compared to experimental results.

There have been multiple experiments dedicated to juncture flow regions, including Simpson [5] and Gand et al.[6] with the ONERA group, but very few were able to obtain measurements in the trailing-edge corner separation, on a swept wing configuration. Simpson's work focused more on the leading edge horseshoe vortex, while ONERA's experiment was an unswept wall-mounted wing.

NASA, through its Transformational Tools and Technologies Project (TTT) under the Advanced Air Vehicle Program, is supporting a substantial effort, the Juncture Flow (JF) experiment, to investigate the formation and origin of separation bubbles found on wing-body juncture zones. The experiment intends to collect CFD validation level data in wing-junctures, focusing on the separation onset and progression in the trailing edge. The experiment's model, or Juncture Flow model (JFM), will consists of a sting-mounted swept-wing and fuselage model, with a Laser Doppler velocimetry (LDV) system inside the fuselage (as opposed to the traditional LDV system mounted behind the wind tunnel walls). The goal is to observe the onset and growth of the separation bubble. Placing the LDV system inside the fuselage provides a way to measure the leading-edge and trailing-edge juncture regions.

The JF experiment had planned to test at transonic cruise conditions. However, a quick sizing study, done with NASA's CFD solver Overflow, ${ }^{7}$ showed that the desired model size in a transonic wind tunnel (in this case NASA Ames $11 \mathrm{ft}$. transonic wind tunnel) would cause significant blockage. The desired model size is an $8 \%$ model, based on the full scale Common Research Model. ${ }^{2}$ The Juncture Flow Committee thus shifted the test to target NASA Langley's 14-by-22 Foot Subsonic Wind Tunnel. ${ }^{8}$

The Juncture Flow Committee searched for a wing candidate that ideally, would be symmetric, and have zero, to small, to large side-of-body separation with changes in angle of attack. Multiple candidates were looked at, some

\footnotetext{
* Member AIAA, Research Scientist,Computational Aerosciences Branch, ARC, MS 258-2

${ }^{\dagger}$ Associate Fellow, AIAA, Senior Research Scientist, Computational Aerosciences Branch, ARC, MS 258-2

${ }^{\ddagger}$ Research Scientist, Flow Physics and Control Branch,LaRC, Mail Stop 170.

$\S$ Research Scientist, Flow Physics and Control Branch,LaRC, Mail Stop 170.
} 
even designed by committee members. These candidates were predominantly evaluated using Overflow. It became apparent that not all the initial design criteria could be met. Large side-of-body separation was heavily influenced by wing loading, and symmetric wings could not achieve that wing loading unless at very high angles of attack. Cambered twisted wings at even very negative angles of attack, still showed small side-of-body separation bubbles.

Six wing configurations, which combined met all the goals, were selected for further testing. Some of the wing candidates were designed with a leading-edge horn. Previous work by Barber ${ }^{9}$ and Gand $^{6}$ showed that a leadingedge horn would change the strength of the horseshoe vortex and the resulting side-of-body separation. These 6 wing configurations will be discussed in section II. Up to this point CFD was the primary evaluator for the configurations, yet as described above, there are questions on how accurate CFD can be for juncture flows.

The Juncture Flow Committee thus decided to commission a few smaller, low cost risk reduction experiments to help further evaluate the wing candidates for the final experiment. A series of three risk reduction tests were performed:

1. Fluid Mechanics Lab (FML) Test Cell 2 (TC2) at NASA Ames Research Center 3\% semispan model,

2. Virginia Tech Stability Tunnel $2.5 \%$ fullspan model,

3. NASA Langley 14-by-22 Ft. Subsonic Wind Tunnel 6\% fullspan model.

CFD was run in conjunction with the tests to help better understand the flow, the wall effects, and possible differences in CFD and experimental methods.

The TC2 risk reduction experiment was designed as a semi-span wall-mounted 3\% model, targeting a lower Reynolds number of 0.62 million based on a Yehudi crank chord of 8.2 inches. ${ }^{10}$ The correlation between the TC2's results and CFD were not as strong in both the side-of-body separation, and the wing-fuselage boundary layer surveys. The fuselage nose and wall junction produced a large horseshoe vortex that the CFD simulations could not fully capture. This test affirmed that the wall effects from a side-wall mounted model were nontrivial and could affect the side-of-body separation in a negative way.

The Virginia Tech risk-reduction experiment was a sting-mounted fullspan 2.5\% model test, at a low Reynolds number of 0.62 million based on a Yehudi crank chord of 6.9 inches. The CFD results did show stronger correlation with the Virginia Tech results, ${ }^{11}$ which is probably due to the sting mounted model instead of a wall mounted model. The low Reynolds number did cause the wing tips to separate at the higher angles of attack, which both oil-flow and CFD results confirmed. This test confirmed a sting-mounted model was the ideal choice.

The third risk reduction experiment was performed in NASA Langley's 14-by-22 Ft. Subsonic Wind Tunnel, with a $6 \%$ scale full-span model (versus the $8 \%$ final juncture flow experiment scale), at a higher Reynolds number of 2.4 million based on the Yehudi crank chord of 16.5 inches. At $6 \%$ scale, the wing span is roughly 98.3 inches, and the fuselage is approximately 8 feet long. The experiment will test the the 6 wings detailed in Section II. CFD simulations, using NASA's Overflow, ${ }^{7}$ were performed as well in both free air and with wind tunnel walls. Some brief comparisons will be made between the CFD and the $6 \%$ risk reduction experimental results (for the rest of the paper, the $6 \%$ risk reduction experiment will be referred to as just the experiment). For this paper, results will be limited to predominantly CFD surface streamlines and experiment's oil flow results. Additional experimental results, including data from pressure taps and Kulite pressure transducers will not be shown, see Kegerise and Neuhart [12] for the full experimental results.

This paper will first cover the selected wing configurations, with a brief description of each. The CFD setup and post-processing method will be presented next, followed by a brief description of the relevant $6 \%$ risk reduction experiment setup. The CFD and experimental results will be shown next, and a brief comparison of the results will be included.

\section{Wing Configurations}

A large number of wing candidates were evaluated with CFD, and six wing candidates were chosen to be tested in the series of risk reduction tests. The desired candidate would be symmetric and have zero-to small-to large side-ofbody separation with changes in angle of attack. These wing candidates were chosen because they exhibited some of the desired criteria. These six wing candidates are:

- DLR-F6 wing (F6),

- DLR-F6 wing with a leading-edge horn,

- NACA 0015 (root) symmetric wing,

- NACA 0015mod (root) symmetric wing,

- F6S12, a symmetric F6 variant,

- COCA, a custom designed symmetric wing.

A brief description of the wing candidates are below. A more in depth description for all the wing candidates can 
be found in Rumsey et al.[11]. The DLR-F6 (F6) wing, which is the same wing used in DPW3, has shown significant side-of-body separation in both experiments and CFD simulations. A leading-edge horn was added to the DLR-F6 wing, to assess the horn's effect on the side-of-body separation. The NACA 0015 and NACA 0015 mod were chosen due to the smaller expected side-of-body separations. The NACA 0015, the NACA 0015mod, the F6S12, and the COCA wings were all designed with a leading-edge horn. The NACA 0015 and NACA 0015 mod wings blend into a NACA 0012 at the Yehudi crank chord, and a NACA 0010 at the wing tip. The F6S12, which is a symmetric F6 variant, was an attempt to satisfy the symmetry goal of the juncture-flow committee. The COCA, short for CoderCampbell wing, is a symmetric wing designed with CDISC $^{13}$ using skin-friction constraints. Figure 1 shows the wing root airfoil profiles for each of the wings, and the wing planform (top) view.

Over the course of the test, the model was configured with the different wing pairs listed in Table 1.

Table 1. Wing Configurations

\begin{tabular}{cccccc}
\hline Configuration & Port Wing & Starboard Wing & Experiment Data & CFD-Air Data & CFD-WT Data \\
\hline 1 & F6 no-horn & F6 w/horn & Yes & Yes & Yes \\
2 & $0015 \mathrm{w} /$ horn & 0015mod w/horn & Yes & Yes & $\mathrm{No}^{1} /$ Yes \\
3 & F6S12 w/horn & COCA w/horn & Yes & Yes & $\mathrm{No}^{2}$ \\
\hline
\end{tabular}

${ }^{1} 0015$ No Horn wing was run instead for CFD-WT case.

${ }^{2}$ F6S12-COCA configuration was not run in CFD-WT.

\section{Computational Fluid Dynamics, Overflow}

Preliminary CFD solutions at the wind tunnel conditions were performed with Overflow. Simulations were run with a free air far field (CFD-Air), first, and then select cases with wind tunnel walls (CFD-WT) to assess the wall effects. The subsequent sections will cover how the Overflow simulations were set up.

\section{A. Overflow Setup}

A series of overset grids were used to model the Juncture Flow model. There is a commonality between the grids used in all of the CFD simulations. The grids were built using Chimera Grid Tools. ${ }^{14}$ The JFM consists of a fuselage, and two wings. The fuselage is built from 4 grids, two of which span the length of the fuselage, and two cap grids covering the nose and rear of the fuselage. The wing grids for all the various configurations share a common 6 grid topology. The wing grids consist of two collar grids covering the wing-fuselage junction, two grids spanning the wing, and two wing tip cap grids. Each pair of grids have overlap along the chord, making effectively a front and rear grid. The JFM grids were built in accordance with the best practices as established in the Drag Prediction Workshop. Figure 2 shows the fuselage and left/right wing grids.

The fuselage is symmetric, which allows any combination of wings to be installed. The overall vehicle includes 16 grids, and Table 2 details the various configurations looked at in this study, and the grid point totals for each configuration.

All of the Overflow cases were run with Overflow 2.2L. The $3^{r d}$-order Roe upwind scheme ${ }^{15}$ is used for the convective fluxes, and the implicit solve was done using ARC3D Beam-Warming scalar pentadiagonal scheme. LowMach preconditioning ${ }^{7}$ was used. The Spalart-Allmaras turbulence model with the rotational correction and QCR was used. ${ }^{16}$ All the cases were run fully turbulent.

For the free air cases, the JFM model is imbedded in Overflow's off-body cartesian grid system. Domain connectivity was performed using Overflow's object x-rays. ${ }^{17}$ The far-field domain was set to be 100 chord lengths away. The free air simulations were run at Mach 0.26 at $T=529$ Rankine, with a Reynolds number of 2.4 million based on the Yehudi crank chord. The free air simulations were run at an angle of attack of $-10.0^{\circ}$ to $10.0^{\circ}$ at $2.5^{\circ}$ increments. Figure 3 shows the off-body cartesian grid used in the air cases.

The CFD-Air results were computed using NASA's Pleiades supercomputer on 420 Intel Broadwell cores, for approximately 12 hours of walltime. The cases were all run from a cold start, meaning solutions were not restarted from a lower angle of attack. No analysis was done to see if there are hysteresis effects on the side-of-body separation. Figure 4 shows an example solver residual and turbulence residual for a CFD-Air case. 


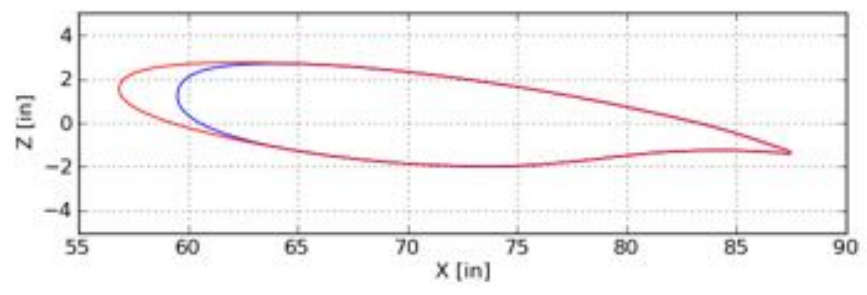

(a) F6 (blue) and F6 with leading-edge horn (red).

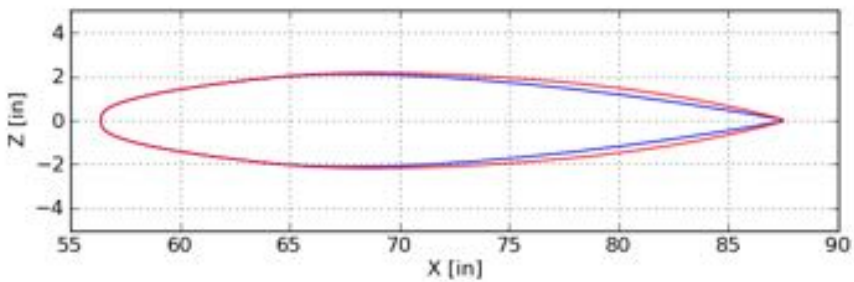

(c) NACA 0015 (blue) and NACA 0015 mod (red) both with a leading-edge horn.

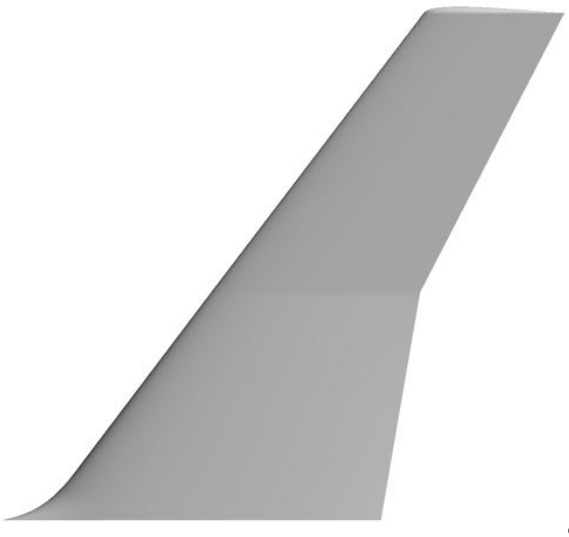

(b) F6 with leading edge horn planform.

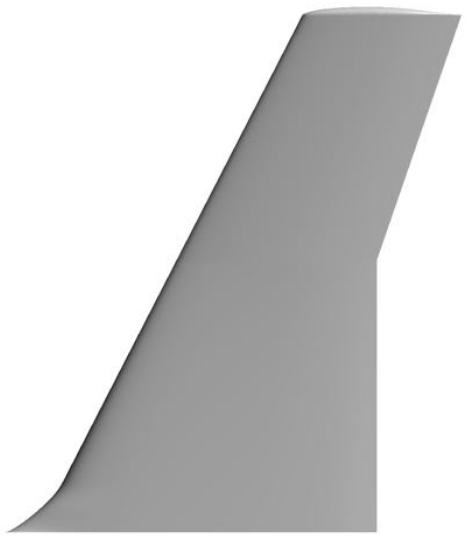

(d) NACA 0015modwith leading edge horn planform.

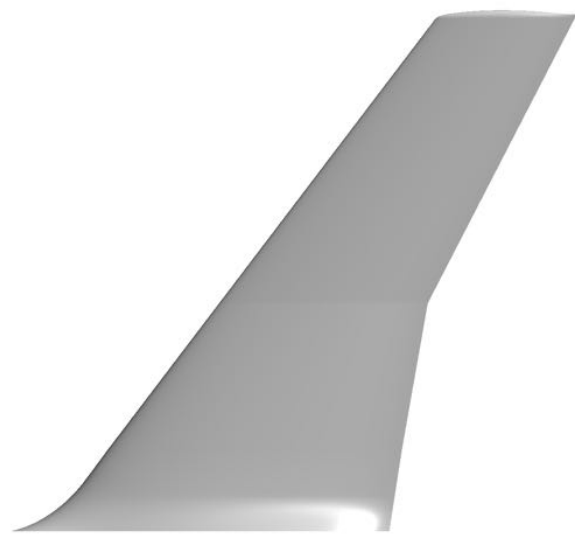

(f) F6S12/COCA with a leading-edge horn planform. $\mathrm{g}$

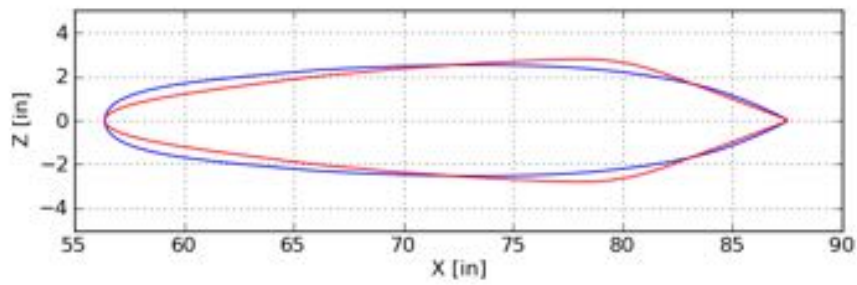

(e) F6S12 (blue) and COCA (red) both with a leading-edge horn. 


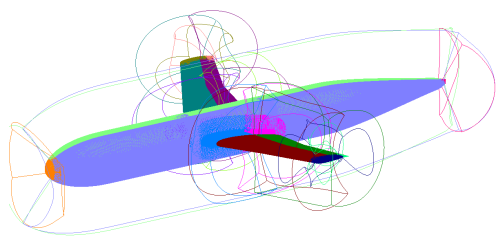

(a) Juncture flow grids with the F6 no-horn (port) and F6 with-horn (starboard).

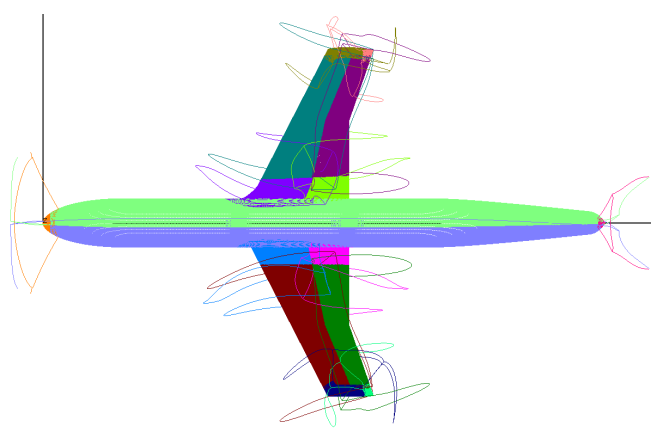

(b) Juncture Flow grids with the F6 no-horn (port) and F6 with-horn (starboard) top view.

Figure 2. Example of the juncture flow volume grids, contains 16 grids.

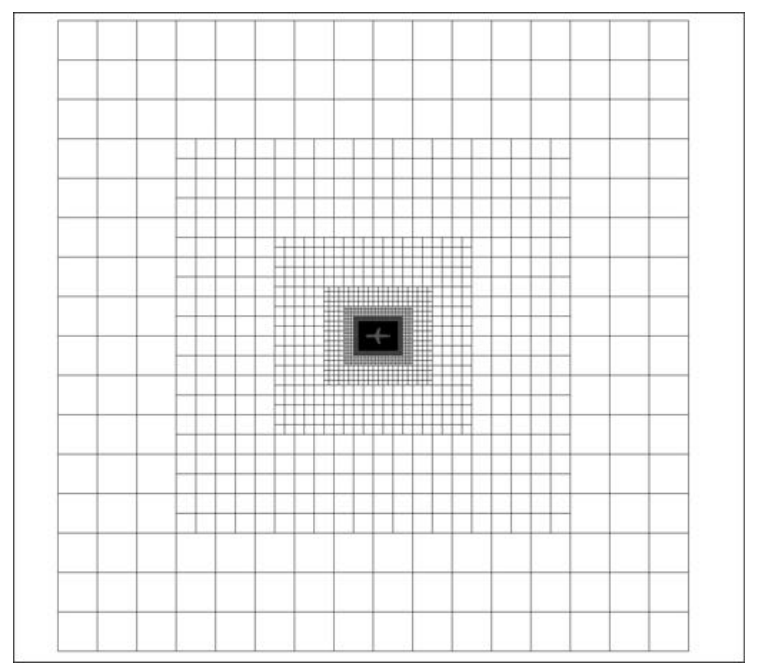

(a) Juncture flow far-field off-body grids $x-y$ view.

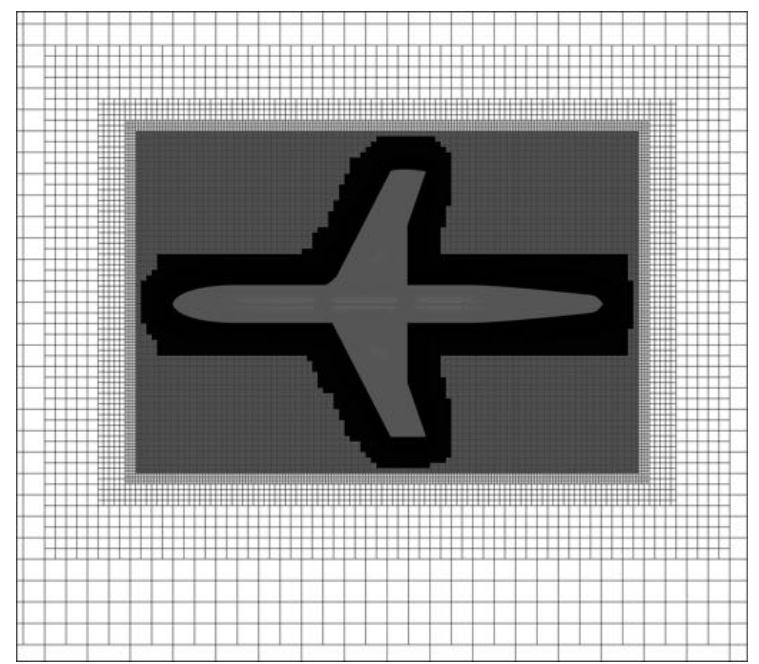

(b) Juncture flow off-body grids $\mathrm{x}-\mathrm{y}$ zoomed in view.

Figure 3. Example of the juncture flow off-body grids for the air cases.

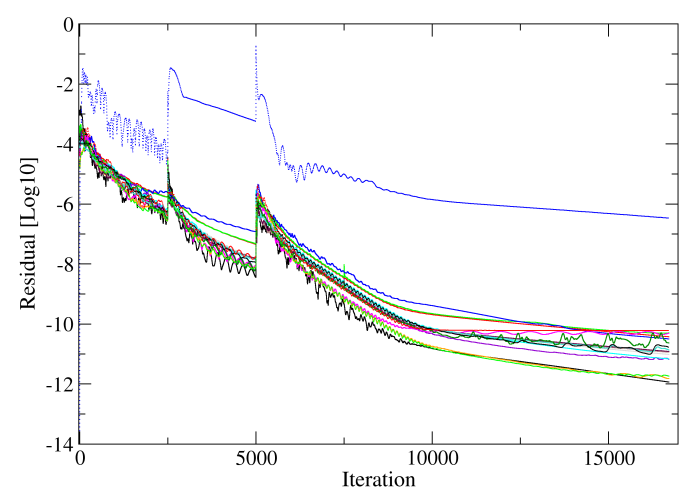

(a) Overflow CFD solver residual.

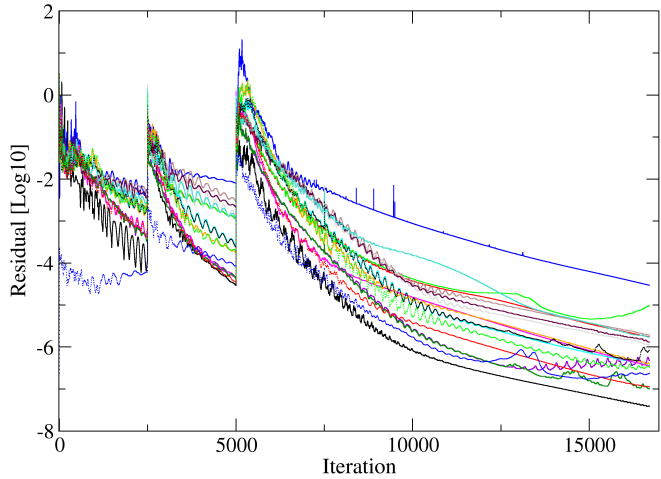

(b) Overflow CFD turbulence residual.

Figure 4. Overflow CFD solver residual and turbulence residual for the in air cases.

For the wind tunnel grids, wall grids were constructed from the as-built laser scanned CAD model, as detailed in Nayani et al.[18]. A total of 12 grids were used to model the $14 \times 22$ wind tunnel. 8 grids model the wind tunnel walls, and 4 core grids model the inside of the tunnel. There are a pair of wall grids, and one core grid for each section (inlet, test section, first diffuser section, second diffuser section). Domain connectivity and hole cutting were performed 
using Overflow's object x-rays as well. ${ }^{17}$ Figure 5 shows the wind tunnel volume grid, and Figure 6 shows a profile and front view of the juncture flow model grid as installed into the wind tunnel grids.

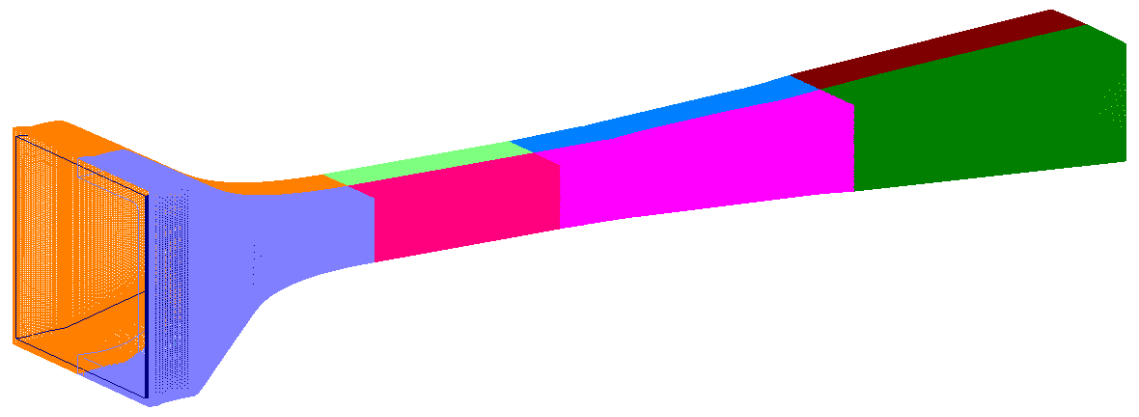

Figure 5. Volume grid of NASA Langley's 14x22 Wind Tunnel, high speed leg.

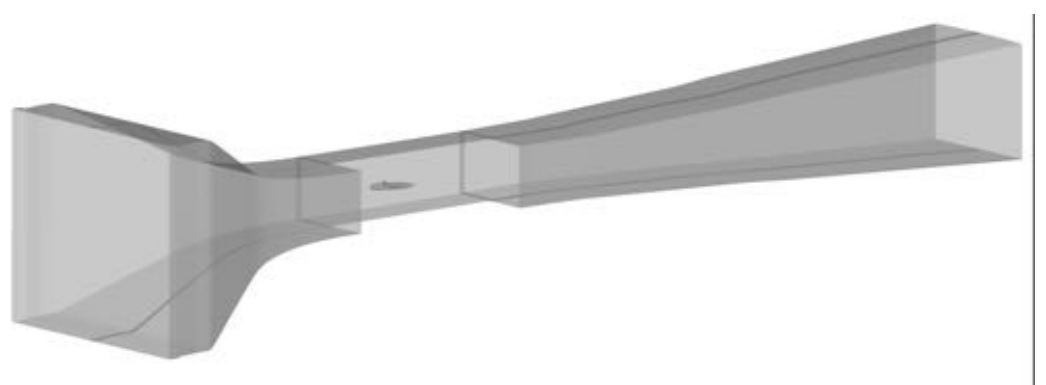

(a) Juncture flow model grid installed in high speed leg of $14 \times 22$ with part of the test section hidden.

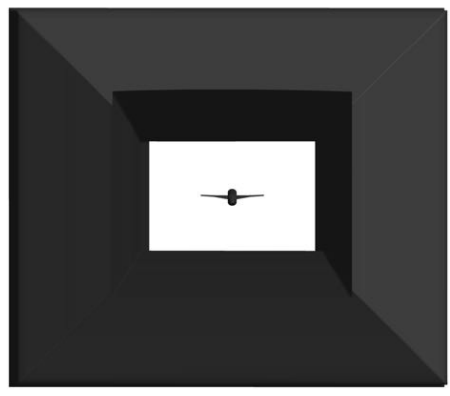

(b) Juncture flow model grid installed in high speed leg of $14 \times 22$ front view.

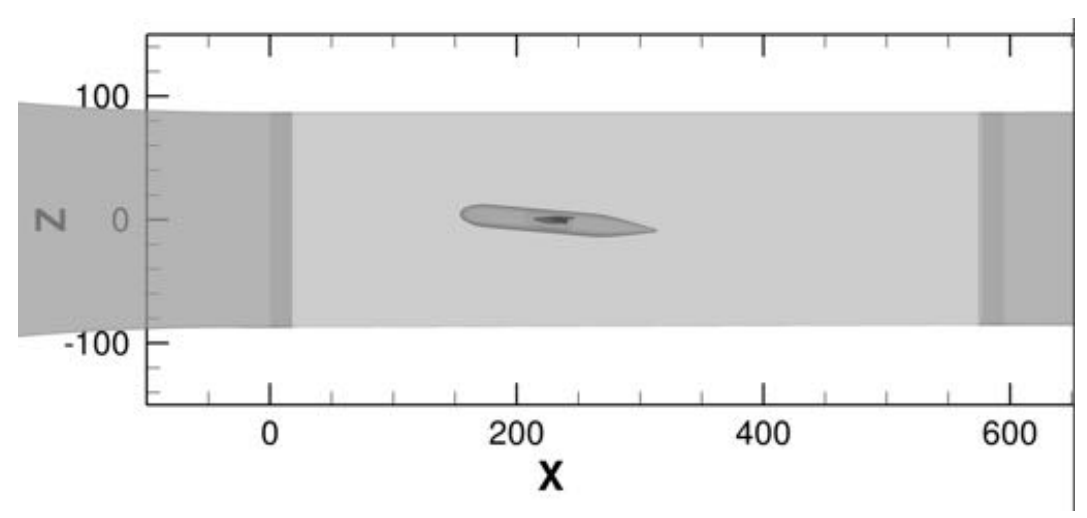

(c) Juncture flow model grid installed in $14 \times 22$, side view focused on the test section.

Figure 6. Example of the juncture flow grids for the wind tunnel cases.

The wind tunnel also was modeled using a reference Mach number of Mach 0.26, a reference temperature of $T=529$ Rankine, and a Reynolds number of 2.4 Million based on the Yehudi crank chord. Stagnation temperature and stagnation pressure based on a reference condition of Mach 0.26 were imposed at the inlet boundary, and a back pressure ratio was specified at the tunnel exit. A combination of the static and stagnation pressure measurements were used to calculate the tunnel speed, and the back pressure was iterated until the wind tunnel reached the desired conditions. More on this method of simulating the wind tunnel can be found at Rumsey et al.[19].

The CFD-WT simulations were run on NASA's Pleiades supercomputer using 1200 Intel Ivy Bridge Cores, for anywhere between 60 to 120 hours of wall time. The wind tunnel simulations take a lot longer to run, due to the need to iterate the back pressure to get the tunnel conditions to match. Warm restarts, or restarting from a previous 
solution at a lower angle of attack, helped cut reduce the overall runtime. Figure 7 shows an example solver residual and turbulence residual for a CFD wind tunnel case.

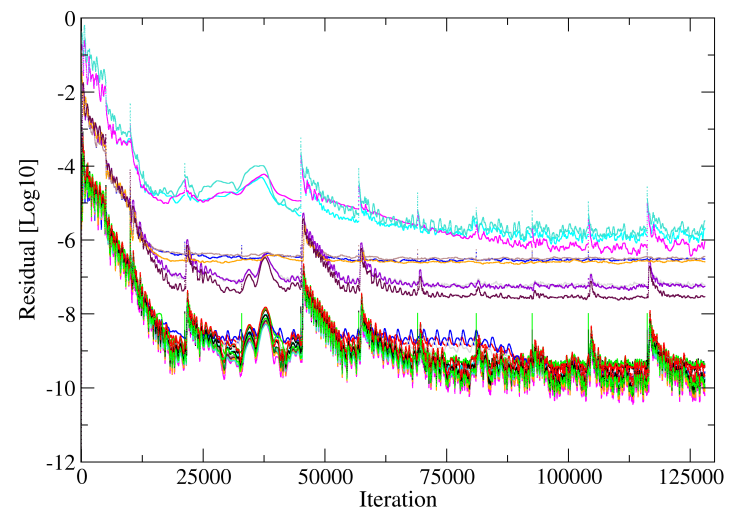

(a) Overflow CFD solver residual.

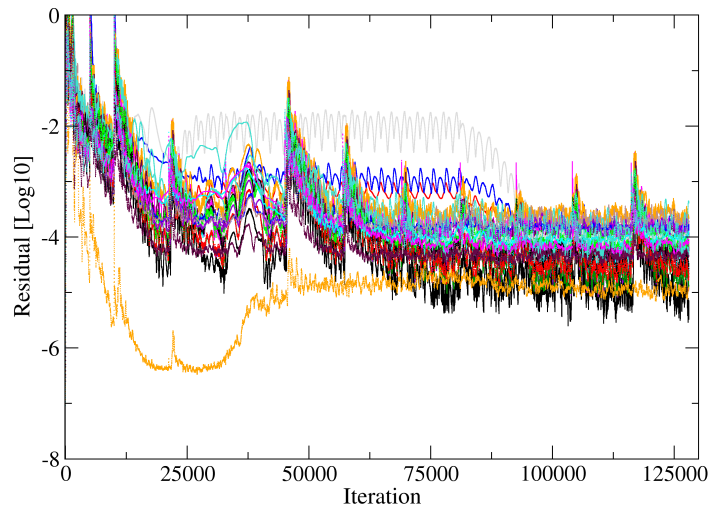

(b) Overflow CFD turbulence residual.

Figure 7. Overflow CFD solver residual and turbulence residual for the wind tunnel cases.

Table 2 outlines the JFM number of grid points and total number of grid points for each of the CFD cases. The near-body grid points refer to the total number of grid points used to model just the JFM, not including the far-field or wind tunnel walls grids. The total grid points includes all of the volume grids, including the far-field or the wind tunnel walls.

Table 2. Overflow Grid Point Summary

\begin{tabular}{cccccc}
\hline Configuration & Port Wing & Starboard Wing & Case & Near-Body Grid Points & Total Grid Points \\
\hline 1 & F6 no-horn & F6 w/horn & Air & $58,930,716$ & $104,221,593$ \\
1 & F6 no-horn & F6 w/horn & WT & $58,930,716$ & $116,691,840$ \\
2 & 0015 w/horn & 0015mod w/horn & Air & $56,980,503$ & $119,201,940$ \\
2 & 0015 no-horn & 0015mod w/horn & WT & $52,919,412$ & $110,680,532$ \\
3 & F6S12 w/horn & COCA w/horn & Air & $64,006,800$ & $107,536,807$ \\
\hline
\end{tabular}

${ }^{1} 0015$ No Horn wing was run instead for CFD-WT case.

\section{B. CFD Post-Processing}

The CFD cases were post-processed with Tecplot 360EX_2017r1. Tecplot's surface streamlines, when placed on noslip boundary surfaces, propagate according to the normal gradient of the tangential velocity very close to the surface. The velocity gradient is computed from the volume data close to the parent surface's grid. The streamline is then integrated forwards and backwards from the streamline seed point, along the local vector field. ${ }^{20}$

CFD surface streamlines are generally considered to be qualitative measurement, as a tool to help visualize the flow features in a CFD simulation. Surface streamlines are often utilized as CFD's equivalent to oil-flow visualization techniques. In this study, the side-of-body separation width, $w$, and length, $l$, were measured from the surface streamlines. The surface streamlines are seeded on the wing and in the juncture region by using Tecplot's surface streamline rake tool, and then the side-of-body width and length are measured. The width is measured along the span of the wing, and the length is measured along the chord. The measurements are made only on wing root in the trailing edge region. The length measurement point is chosen along the wing root, where the mean separation streamline is approximately located. The width measurement is obtained from the widest streamline that can be traced back to the mean separation point along the length. Figure 8 details the length, $l$, and width, $w$, measurements. The measurements, which are done using by hand using Tecplot's point probe tool, are repeatable within 0.25 inch. However this value should not be taken as the CFD measurement uncertainty. 


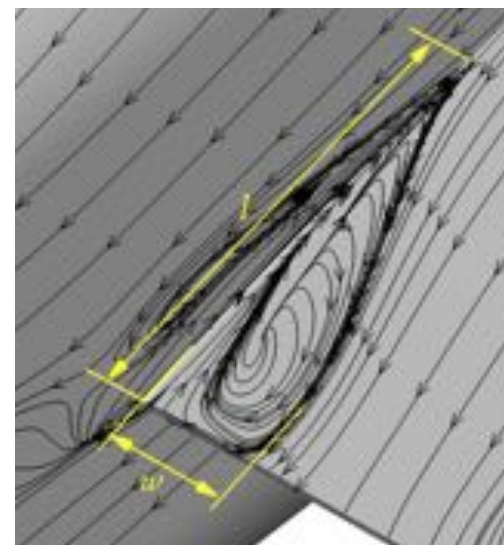

Figure 8. Definition of side-of-body separation length, $l$, and width, $w$, from an example of CFD surface streamlines.

\section{14-by-22 Foot Subsonic Wind Tunnel 6 Percent Risk Reduction Experiment}

The 6 percent risk reduction experiment was performed in the 14-by-22 Ft. Subsonic Tunnel (14x22), and the full results can be found in Kegerise and Neuhart [12]. A description of the relevant experimental setup will be presented below. The subsequent subsections will discuss the $14 \times 22$ wind tunnel, the juncture flow model, and the oil-flow visualization process.

\section{A. 14 -by-22 Ft. Subsonic Wind Tunnel}

The experiment was performed in the Langley 14-by-22 Ft. Subsonic Tunnel, which is a closed-circuit, atmosphericpressure wind tunnel. This test was made in the closed test section mode, which results in a $14.5 \mathrm{ft}$ high and $21.75 \mathrm{ft}$ wide test section. Figure 9 shows the full circuit of the $14 \times 22$ with the high speed leg outlined in blue.

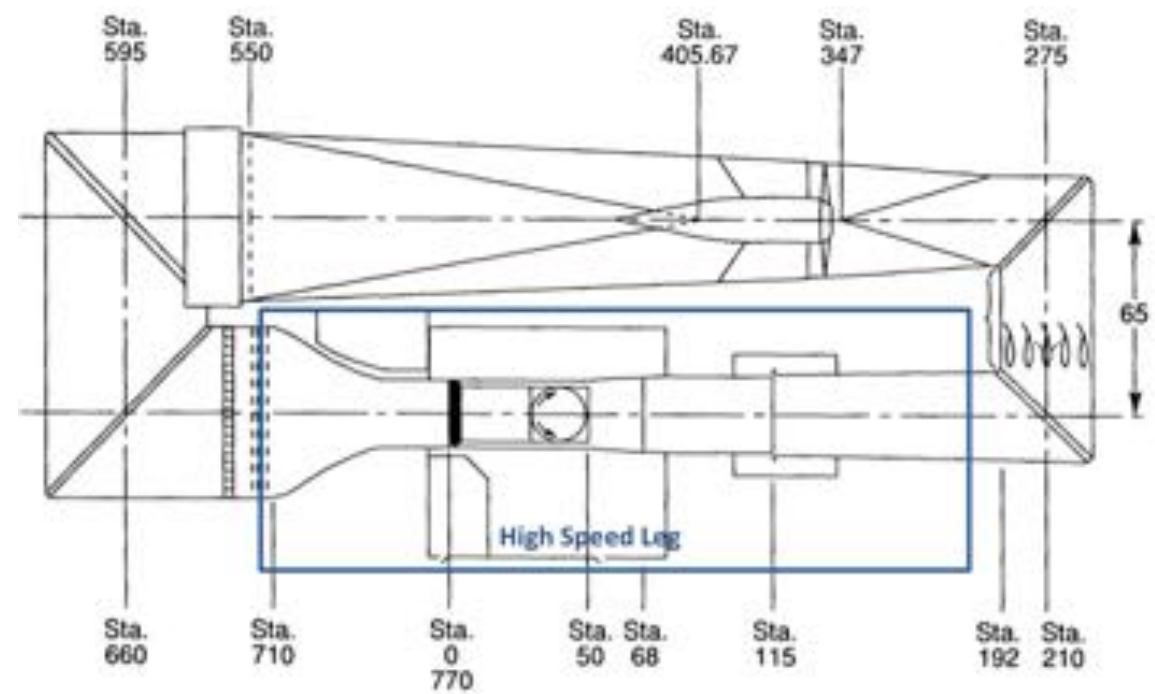

Figure 9. 14x22 Foot Subsonic Wind Tunnel, high speed leg is highlighted in blue.

Further details about the tunnel can be found in Gentry et al.[8]. The flow condition of primary interest for this experiment was $R e_{c}=2.4$ million. The model angle of attack, $\alpha$, was varied at $2.5^{\circ}$ increments from $0.0^{\circ}$ to $10.0^{\circ}$ for the symmetric wings, and $-10.0^{\circ}$ to $10.0^{\circ}$ otherwise. 


\section{B. Juncture Flow Risk-Reduction Model}

The juncture flow risk-reduction model is a large aluminum model consisting of a fuselage ( $12 \mathrm{ft}$ long) and a number of interchangeable wing candidates (wing span of $8 \mathrm{ft}$ ). The model is attached to a long sting that could be raised or lowered via a motorized sting mast to keep a reference point on the model near the center of the test section during an angle-of-attack adjustment.

Photographs of the juncture flow model, as installed in the $14 \times 22$ test section, are shown in Figure 10. Trip dots were used on the fuselage nose, and upper surfaces of the wing candidates. The lower surfaces of the wing candidates were not tripped in this test. Further details of the trip dots can be found in Kegerise and Neuhart [12].

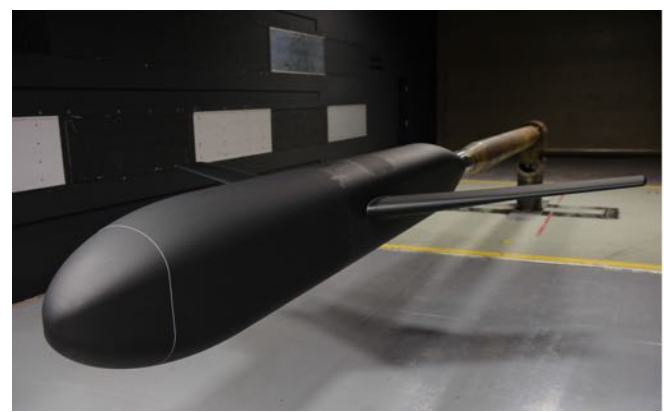

(a) Iso-view

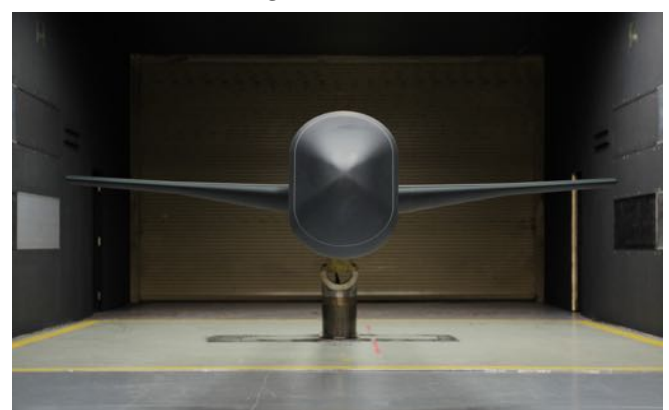

(b) Front-View

Figure 10. Juncture Flow Model as installed in the 14x22 Foot Subsonic Wind Tunnel.

\section{Oil-Flow Visualization}

The oil-flow visualization study was performed on all of the 6 wing candidates. Although the oil-flow visualizations are generally regarded as qualitative in nature, they were used in the present study to obtain measurements of the width and length of the side-of-body separation versus model angle of attack.

The oil-flow material was a mixture of 1 part titanium dioxide (TiO2), 2 parts kerosene, and 0.3 parts oleic acid. The tunnel was ramped up to the desired chord Reynolds number and a live video feed was used to determine when the oil-flow material stopped flowing. After the run, post-test imagery of the oil-flow visualization was acquired. Close-up images of the side-of-body separation, the wing leading-edge region, and any other flow features of interest from a given run were acquired with 12 megapixel digital SLRs.

Generally, the side-of-body separations are marked by a diffuse band of oil-flow material at the boundary of the separation. This is due to the vortical nature of the side-of-body separation and the "history" of the oil-flow development as a run proceeds. As such, it is difficult to say precisely where the mean separation line is located. The reported length and width measurements, are taken from the outer extent of this oil-flow band. An example width, $w$, and length, $l$, measurement is shown in Figure 11. It is likely that the true length and width bounding the mean separation line is less than what is reported here. A ruler with $1 \mathrm{~mm}$ divisions was used to measure the length and width of the side-of-body separation.

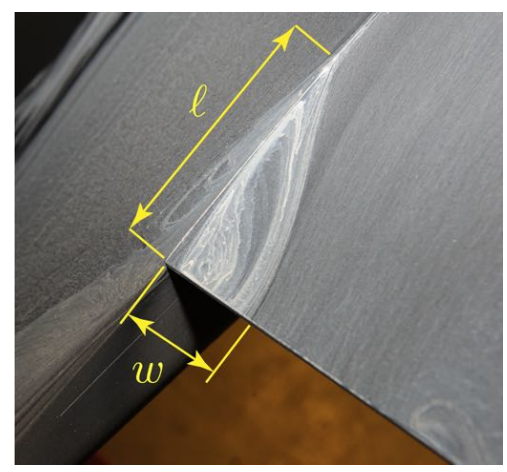

Figure 11. Definition of side-of-body separation length, $l$, and width, $w$, from an example of oil-flow visualization. 


\section{Results}

The computational simulations computed in air and with wind tunnel walls, are compared with the experimental results from the $6 \%$ risk reduction wind tunnel experiment. ${ }^{12}$ Comparisons for the measured side-of-body separation widths, and lengths, for configurations 1 and 2 at $\alpha=5^{\circ}$ will be presented. The remaining surface streamline figures and oil-flow figures for the rest of the cases are in the appendix.

Not all of the experimental results will be shown. Additional experimental results including infrared imaging to determine boundary layer transition and unsteady pressure data from Kulite pressure transducers, can be found in Kegerise and Neuhart [12].

\section{A. Configuration 1: F6 (port), F6 with leading edge horn (starboard)}

Configuration 1 has the F6 wing with no horn on the port side, and the F6 wing with a leading-edge horn on the starboard side. Figure 12 shows the side-of-body separation for all the results at $\alpha=5^{\circ}$. Note that the perspective views between the figures are different, so relative bubble sizes cannot be ascertained from these views. The relative sizes are presented in 13. The starboard wing, which has the leading edge horn shows a larger side-of-body separation than the port wing. There is very little difference in the side-of-body bubble shape between the wind tunnel and air cases, and the surface streamlines from CFD and oil-flow results from the experiment are very similar. Figures $12 b$, and $12 \mathrm{~d}$, and $12 \mathrm{f}$ all show signs of streamlines/oil-flow that turn towards the wing-tip at the trailing edge. These streamlines and oil-flow, show signs of trailing edge separation that can be traced back to the leading edge horn. This effect is present in all of the F6 with a leading edge horn cases at angles of attack $\geq 5^{\circ}$.

Figure 13 compares the side-of-body separation bubble lengths and widths for all the cases. The experimental results will be shown in red, CFD-Air results in green, and CFD-WT results in blue. The dashed lines represent the port wing, and the solid lines represent the starboard wing. The experimental results show error bars, which are derived from repeat runs using slightly different oil viscosity, representing a 95\% confidence interval. Since the images from CFD and experiment are not at the same scale, it makes sense to look at the measured values for qualitative comparisons. The trends between the computational predictions and the experimental measurements are very similar. CFD tends to underestimate the bubble length at lower angles of attack, and then match fairly closely at higher angles of attack. The CFD bubble widths are a little lower than the experimental results. The additional cases for configuration 1 are shown in the appendix. 


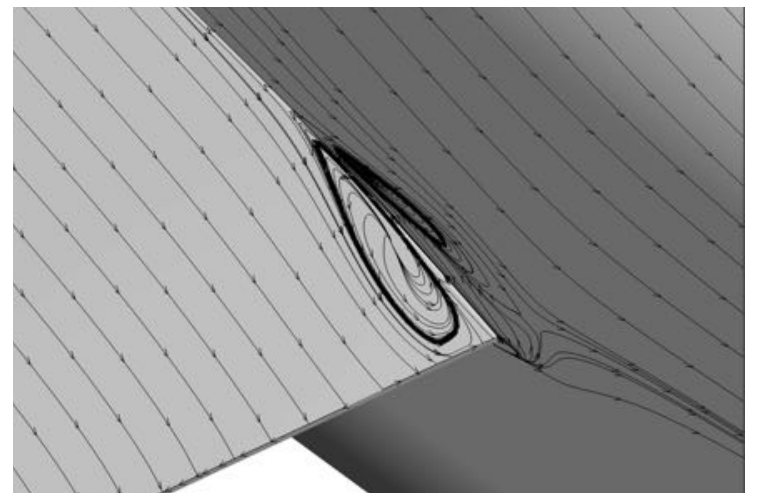

(a) F6 no-horn (port side), Overflow Air

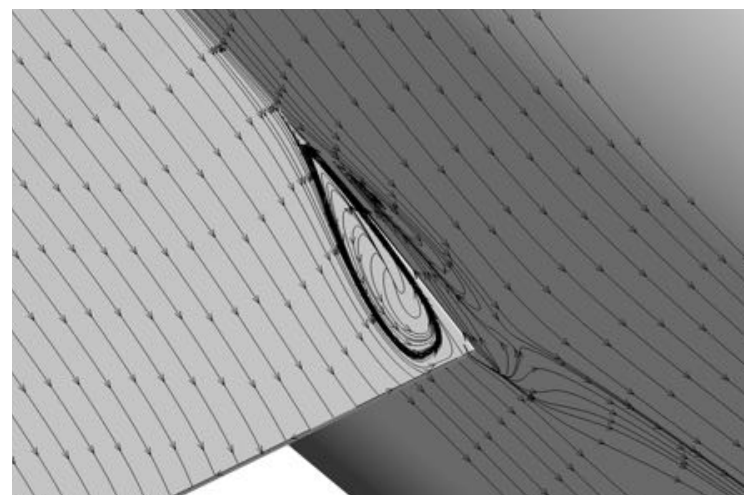

(c) F6 no-horn (port side), Overflow WT

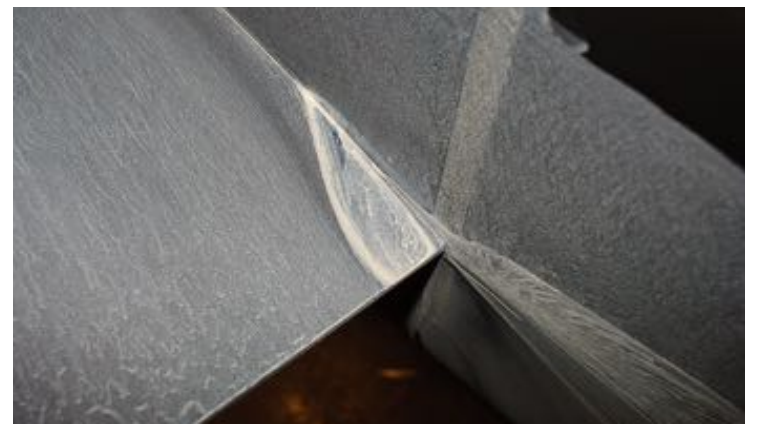

(e) F6 no-horn (port side), Experiment

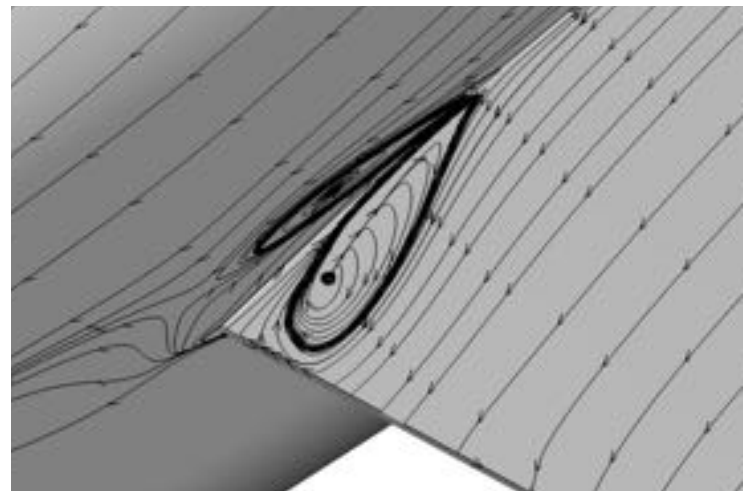

(b) F6 with-horn (starboard side), Overflow Air

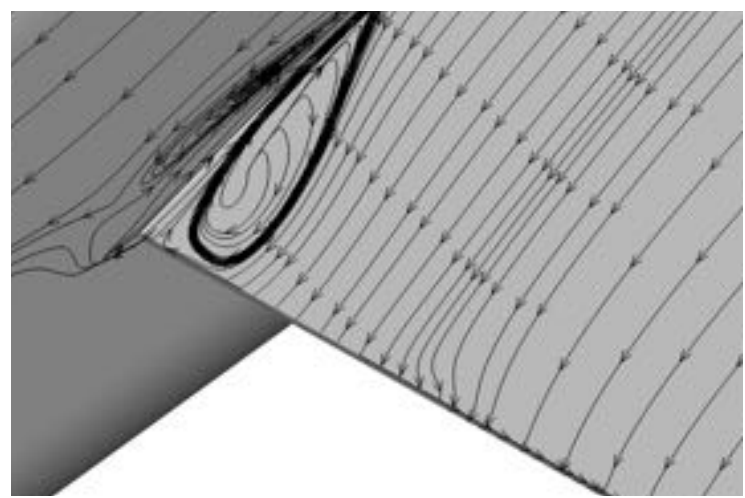

(d) F6 with-horn (starboard side), Overflow WT

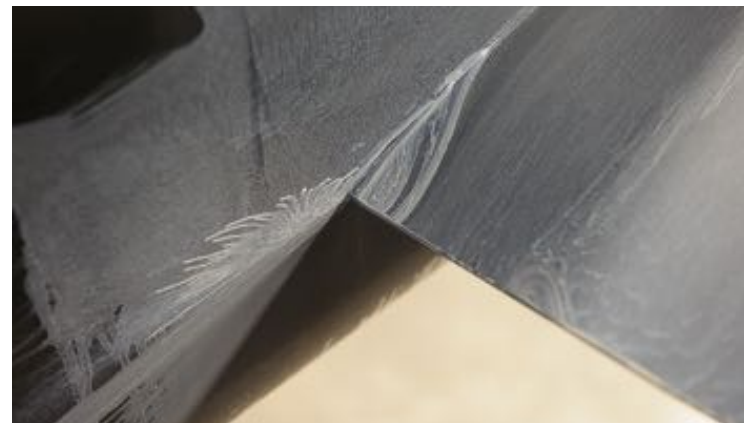

(f) F6 with-horn (starboard side), Experiment

Figure 12. Side-of-body separation comparison at $\alpha=5.0^{\circ}$, Configuration 1 F6 (port), F6 with-horn (starboard), 


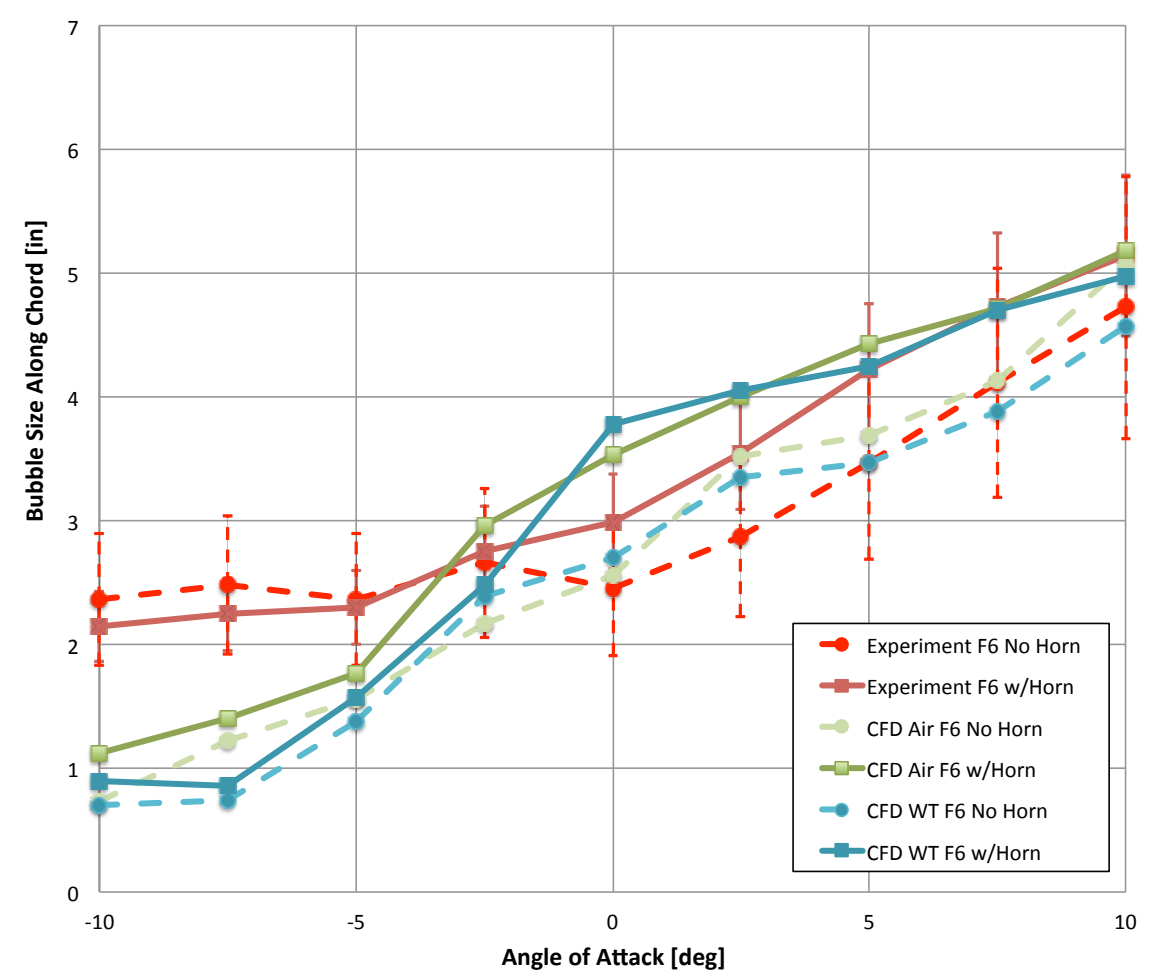

(a) Side-of-body separation length vs model angle of attack comparison.

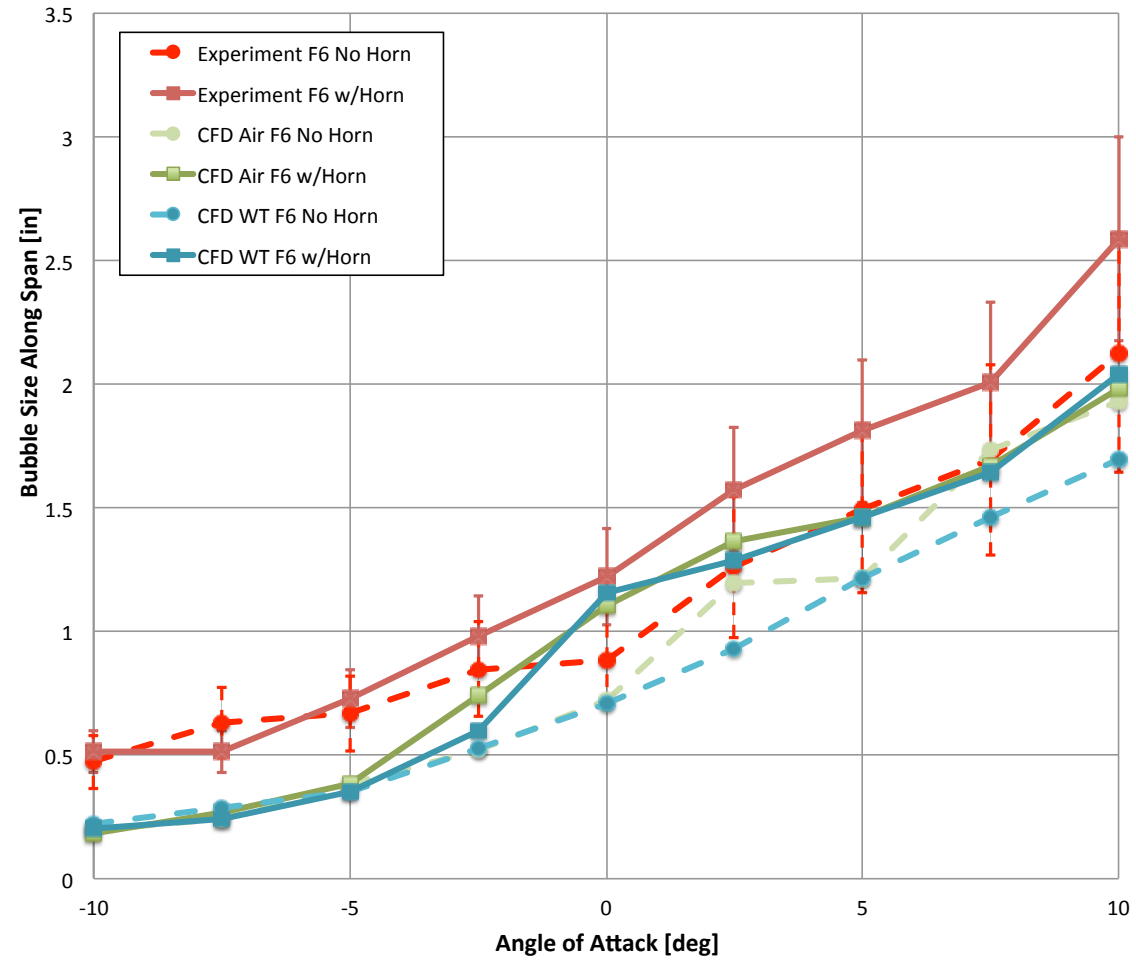

(b) Side-of-body separation width vs model angle of attack comparison.

Figure 13. Side-of-body separation measurement comparison, Configuration 1 F6 (port, dashed line), F6 with-horn (starboard, solid line). 


\section{B. Configuration 1: F6 Leading Edge}

The horseshoe vortex generated by the wing-root leading edge can heavily influence the trailing edge side-of-body separation. Figure 14 compares the leading-edge profiles for the CFD with wind tunnel walls and experimental oilflow at $\alpha=5^{\circ}$. Note: the view angle for the CFD and experiment are slightly different. There is evidence of a large horseshoe vortex on the F6 port wing, on both the CFD and experimental results, while the starboard wing has a horseshoe vortex, but it is attached to the leading-edge horn. On the port wing, the area between the wing leading edge and separation line show evidence of scrubbing due to the vortical flow, since the oil-flow pigment appears thinner in that region.

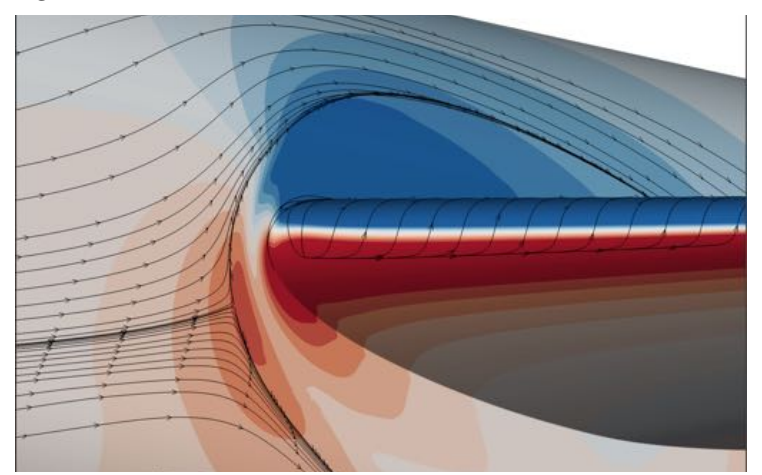

(a) F6 LE no-horn (port side), Overflow WT

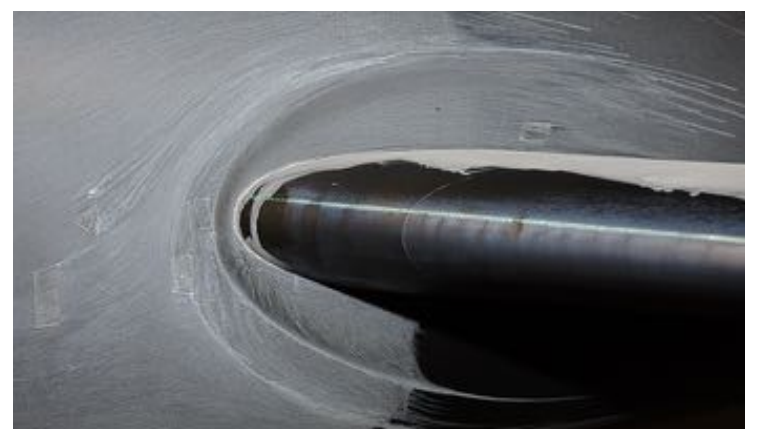

(c) F6 no-horn (port side), Experiment

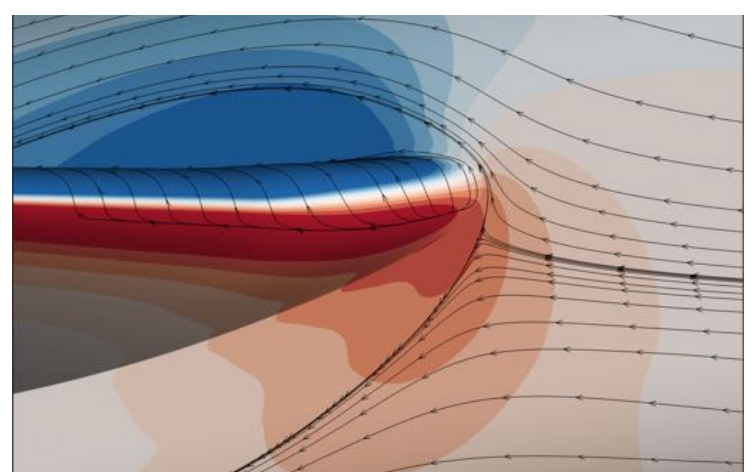

(b) F6 LE with-horn (starboard side), Overflow WT

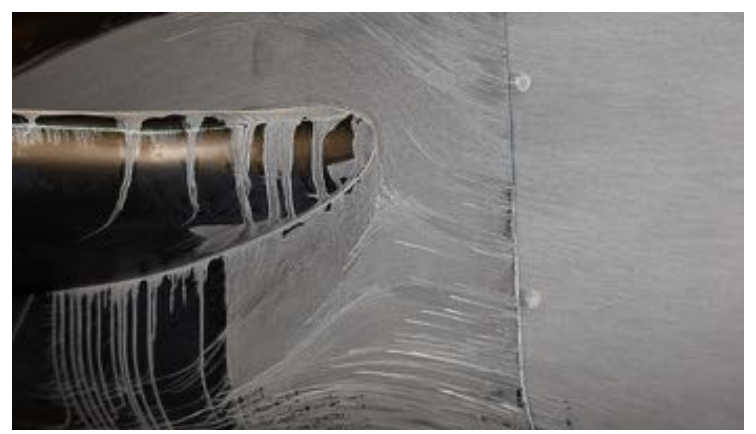

(d) F6 with-horn (starboard side), Experiment

Figure 14. Leading-edge comparison at $\alpha=5.0^{\circ}$, Configuration 1 F6 (port), F6 with-horn (starboard).

The CFD surface is colored by pressure coefficient $\left(C_{p}\right)$ blue-white-red contours, where blue shows negative values of $C_{p}$ and red shows positive values of $C_{p}$. The surface streamlines for the $\mathrm{F} 6$ port wing show a distinct stagnation point and separation line well upstream of the wing leading edge, which suggests the presence of a large horseshoe vortex.

Several of the oil-flow results for the F6 wing without the leading edge horn, port side, show evidence of scrubbing, which is caused by the mean action of a horseshoe vortex system. The F6 wing with the leading edge horn, starboard side, has a separation line on the fuselage that is attached at the leading edge of the horn. There is a distinct lack of surface scrubbing on all the cases, which suggests that any horseshoe vortex system is relatively weak. Some cases do not show evidence of the stagnation line, which may have been caused by the oil-flow material not having enough mobility to highlight the scrubbing. This is more a limitation of the oil-flow technique. The separation line as depicted by the surface streamlines is very similar to the corresponding oil-flow cases for both wings.

\section{Configuration 2: NACA 0015 (port), NACA 0015mod (starboard)}

Configuration 2 consists of a NACA 0015 with horn on the port side, and a NACA $0015 \mathrm{mod}$ with horn on the starboard side. The $\alpha=5^{\circ}$ cases are shown in Figure 15. The NACA 0015 with horn oil-flow results show a shorter triangular separation shape, while the CFD-Air results show more of a longer and skinnier bubble. The NACA 0015mod CFD separation shapes, however, are more similar to the corresponding experimental results. The CFD-Air, CFD-WT, and oil-flow experimental results for the remaining cases are shown in the appendix. 


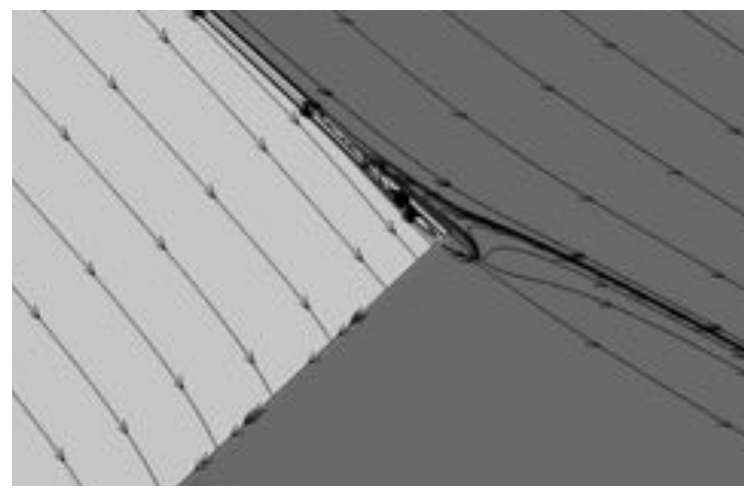

(a) NACA 0015 (port side), Overflow Air

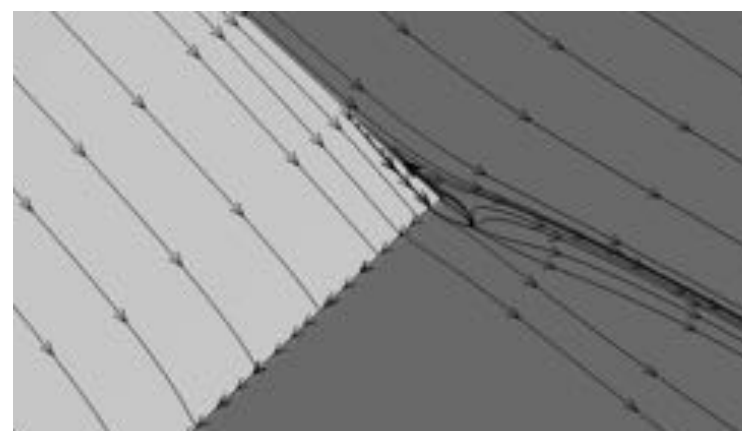

(c) NACA 0015 (no-horn) (port side), Overflow WT

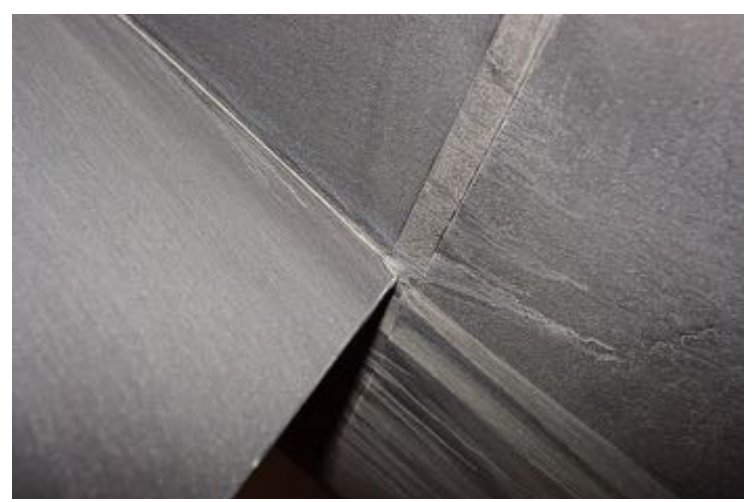

(e) NACA 0015 (port side), Experiment

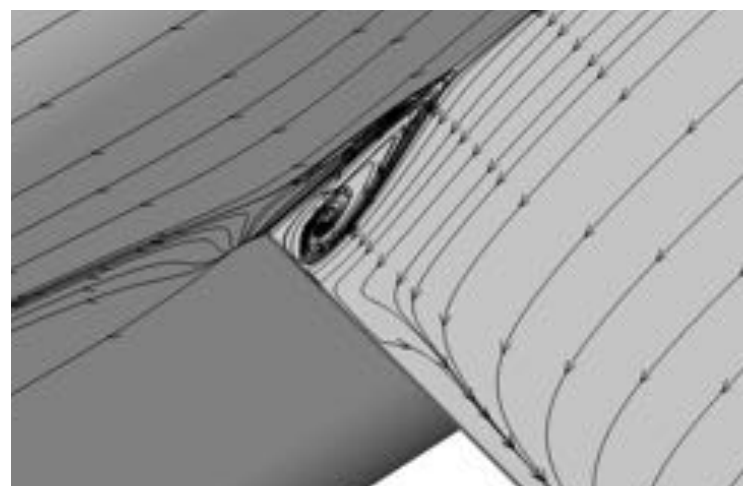

(b) NACA 0015mod (starboard side), Overflow Air

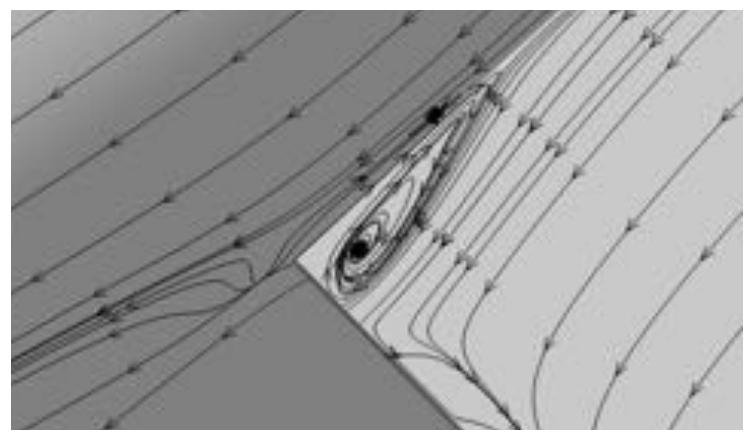

(d) NACA 0015mod (starboard side), Overflow WT

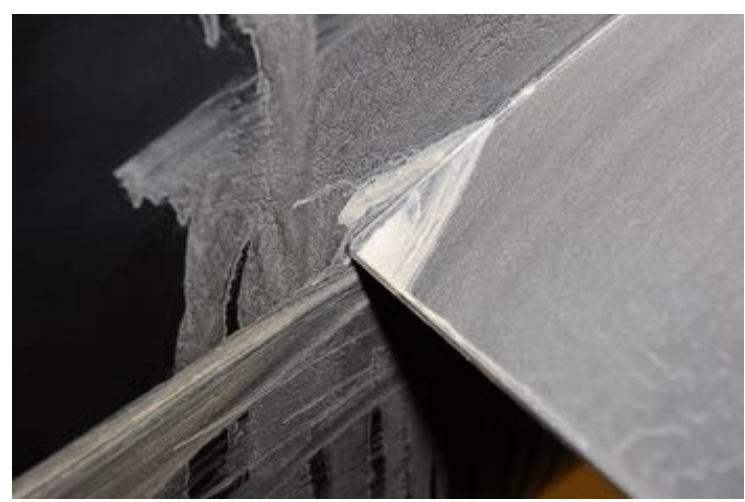

(f) NACA 0015mod (starboard side), Experiment

Figure 15. Side-of-body separation separation comparison at $\alpha=5.0^{\circ}$, Configuration 2 NACA 0015 (port), NACA 0015mod (starboard). 
The sizes of bubble widths and lengths for configuration 2 are shown in Figure 16. The experimental results will be shown in red, CFD-Air results in green, and CFD-WT results in blue. The dashed lines represent the port wing, and the solid lines represent the starboard wing. The NACA 0015mod wing, with the increased trailing edge slope, produces a larger corner separation than the original NACA 0015 wing. The NACA 0015 separation lengths are larger at the lower angles of attack, when compared to the experimental results. The CFD separation widths seem to be lower especially at the higher angles of attack, suggesting that the surface streamlines at these instantaneous CFD solutions, do not completely capture the full separated profile. The port wing on the CFD wind tunnel case doesn't match the actual configuration 2, as this case was run without a leading-edge horn and results in a small discrepancy. The bubble sizes for the port wing in the CFD wind tunnel are smaller, compared to the cases with a leading-edge horn.

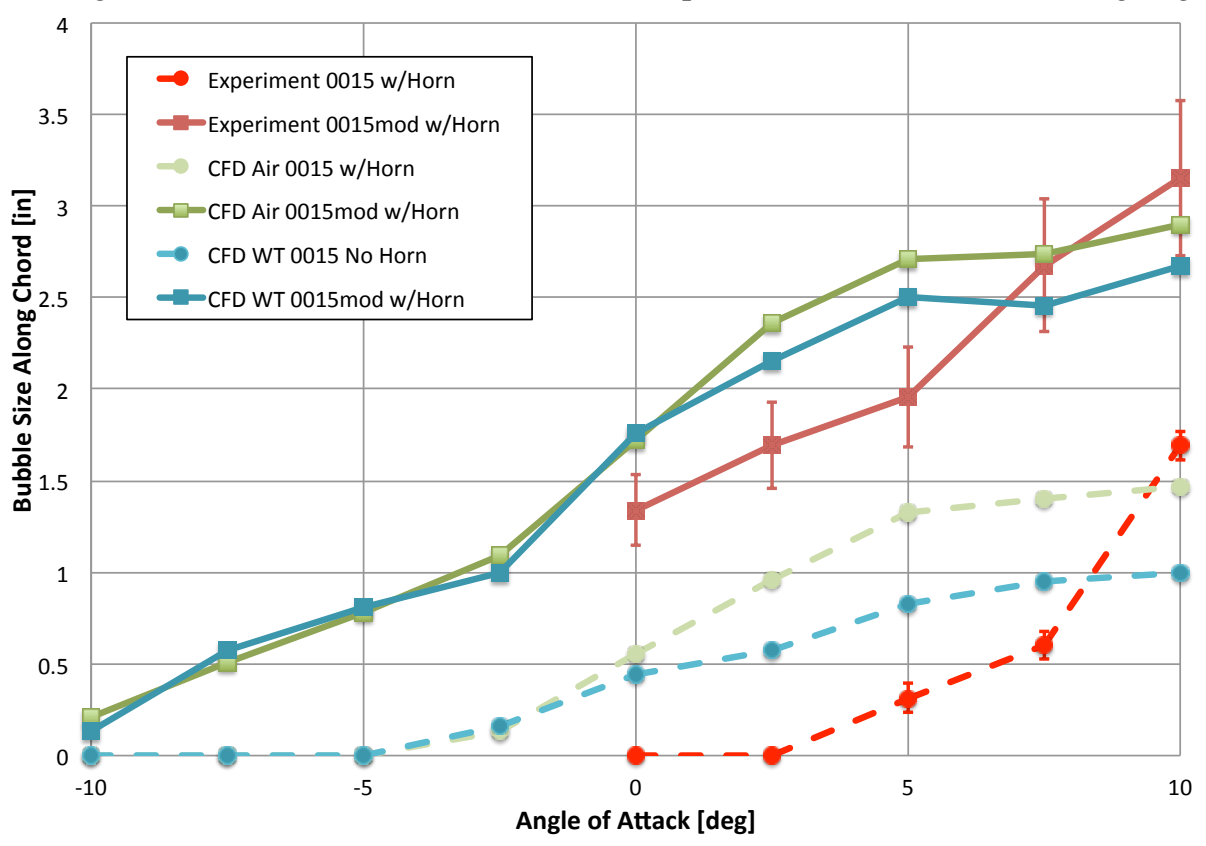

(a) Side-of-body separation length vs model angle of attack comparison.

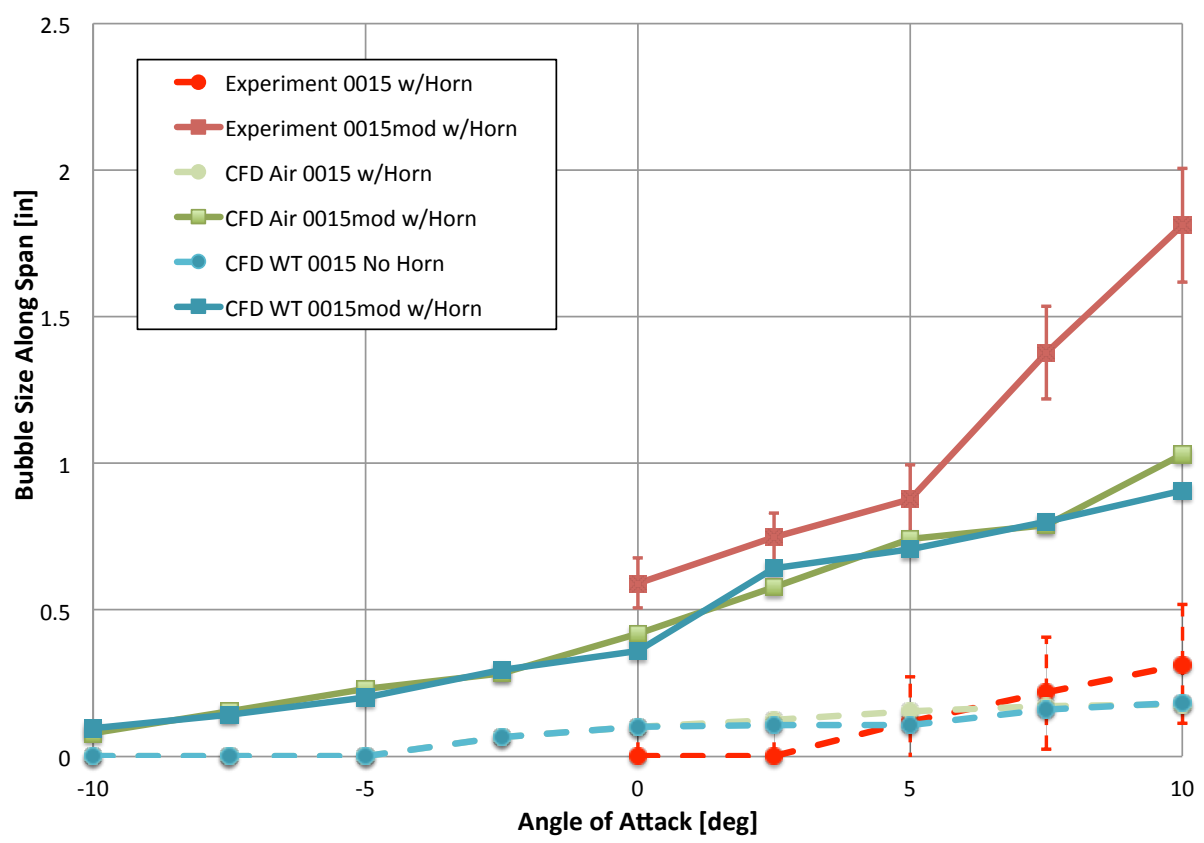

(b) Side-of-body separation width vs model angle of attack comparison.

Figure 16. Side-of-body separation measurement comparison, Configuration 2 NACA 0015 (port, dashed line), NACA 0015mod (starboard, solid line). 


\section{Configuration 3: F6S12 port, COCA starboard}

For configuration 3, the model was configured with the F6S12 with a leading-edge horn on the port wing, and the COCA wing with a leading-edge horn on the starboard wing. The $\alpha=5^{\circ}$ side-of-body separation cases are shown in Figure 17.

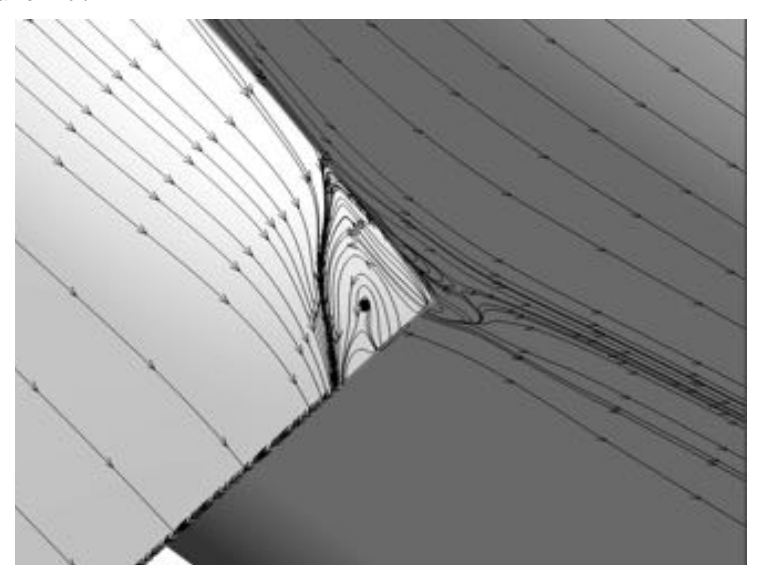

(a) F6S12 (port side), Overflow Air

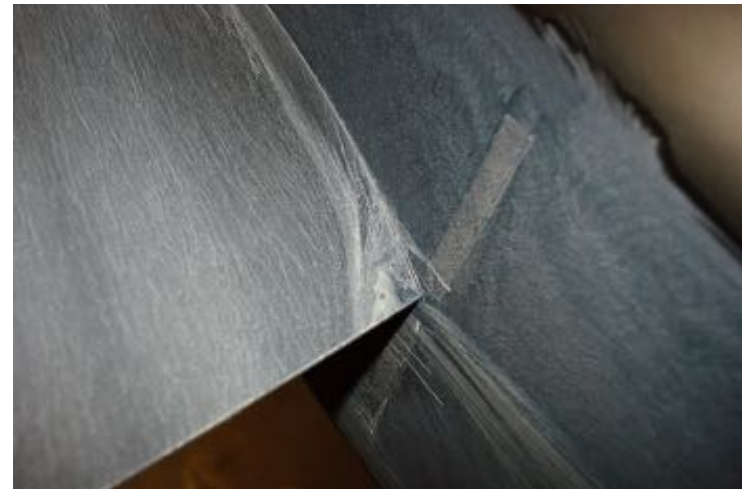

(c) F6S12 (port side), Experiment

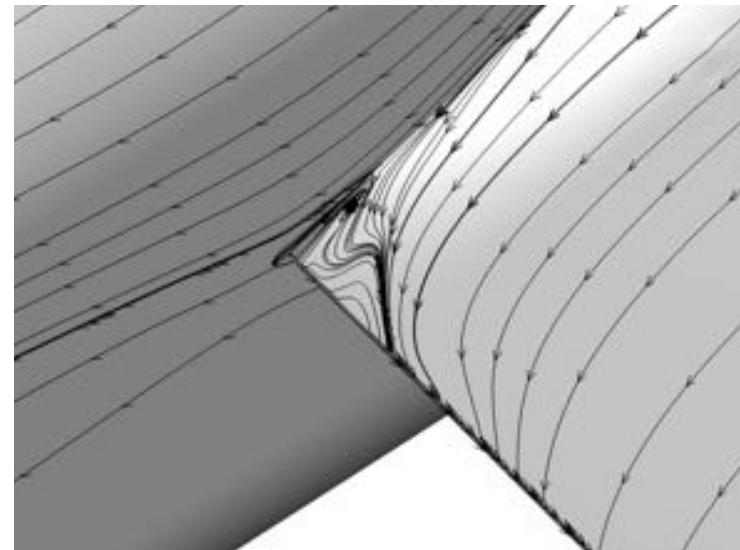

(b) COCA (starboard side), Overflow Air

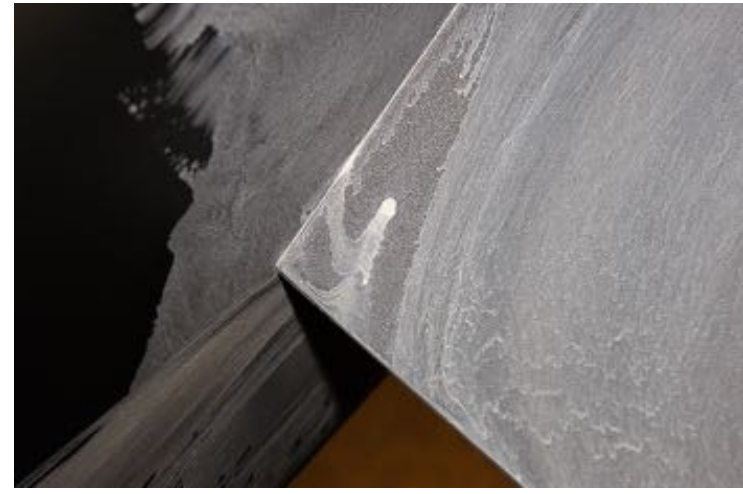

(d) COCA (starboard side), Experiment

Figure 17. Side-of-body separation comparsion at $\alpha=5^{\circ}$, Configuration 3 F6S12 (port), COCA (starboard),

The F6S12 and the COCA results have a complex surface topology as well as a different side-of-body separation shape, which made defining and measuring the width and lengths difficult. The trailing-edge juncture region is not as planar as configurations 1 and 2. No side-of-body length and width measurements were made for these airfoils.

The CFD-Air results suggest a larger separation bubble than what the experiment exhibits. The slope span-wise and chord-wise here is very steep, and the oil may run a little after applying due to gravity. The oil-flow shows flow sweeping down from the fuselage over the steep wing root span-wise, which inhibits the side-of-body separation.

The CFD-Air surface streamlines and oil flow results are shown in the appendix. The CFD-Air results at the lower angles of attack are omitted, due to no visible side-of-body separation. The oil-flow in the lower angles of attack exhibit the same "w" pattern as seen in the CFD-Air results. The CFD and oil-flow results are similar. In the oil flow, what may appear to be separated flow upstream of the "w" region, is really attached and flow is sweeping down and away from the wing root. In the "w" region near the trailing edge, the flow is separated and both CFD and oil-flow show similar topologies. The CFD-Air and oil-flow experimental results for the remaining cases are shown in the appendix.

\section{Conclusions}

A series of CFD cases were run with Overflow, in both free air and with wind tunnel walls. The F6, NACA 0015, NACA 0015mod, F6S12, and COCA wings were all simulated using Overflow. All of the configurations were simulated in air, and the F6, NACA 0015, and NACA 0015mod were simulated also with a computational model 
of the NASA Langley's14x22 wind tunnel walls. The CFD-WT simulations compared very well with the CFD-Air cases. These CFD simulations along with the risk reduction test both helped the Juncture Flow Committee evaluate and downselect the final configurations for the fully instrumented test: the F6 (primary) and 0015 (secondary) wings.

The addition of a leading-edge horn reduced the size of the leading-edge horseshoe vortex, and conversely increased the side-of-body separation. The results were consistent with prior wing-body Juncture flows. ${ }^{5,21}$ However, the presence of the leading-edge horn did result in a consistent region of separated flow at the trailing-edge, just outside of the wing-root junction.

All of the wings exhibited side-of-body separations at all of the angles of attack, except for the NACA 0015 and the COCA wing. The F6, F6 with leading-edge horn, NACA 0015mod, and F6S12 all exhibited side-of-body separations that grew with increasing angle of attack. The NACA 0015 wing did eventually separate at higher angles of attack, but the separation sizes were much smaller than the other wing candidates. The COCA wing, although it exhibits both zero and increasingly-larger side-of-body separations with increasing angles of attack, also exhibited a large trailing-edge separation just outside of the corner region. Overall all of the CFD cases followed similar trends seen in the 6\% risk reduction experiment, and the results compared well qualitatively.

\section{Acknowledgments}

The authors would like to thank the NASA Transformational Tools and Technologies Project for support of the research presented in this paper. The authors would also like to thank Chris Rumsey for leading the Juncture Flow Committee, and the team members of the Juncture Flow Committee. From NASA Langley, these people include: Jan-Renee Carlson, Judy Hannon, Luther Jenkins, Kevin Disotell, Joe Morrison, Bil Kleb, Cathy McGinley, Mujeeb Malik, Mark Cagle, Sandy Webb, P. Balakumar, Don Smith, Andy Davenport, and Frank Quinto. Others include John Vassberg, Tony Sclafani, Mike Beyer, Neal Harrison, Peter Hartwich, and Philippe Spalart from Boeing; Roger Simpson and Gwibo Byun from AUR; Aurelien Borgoltz and Todd Lowe from Virginia Tech; Bill Oberkampf; Jim Coder from University of Kentucky; and James Bell, Greg Zilliac, Nettie Roozeboom, and Laura Simurda from NASA Ames. 


\section{References}

1“CFL3D/OVERFLOW Results for DLR-F6 Wing/Body and Drag Prediction Workshop Wing," Journal of Aircraft, Vol. 45, No. 3, 2008, pp. $762-780$

${ }^{2}$ Vassberg, J., Tinoco, E., Mani, M., Brodersen, O., Eisfeld, B., Wahls, R., Morrison, J., Zickuhr, T., Laflin, K., and Mavriplis, D., “Abridged Summary of the Third AIAA Computational Fluid Dynamics Drag Prediction Workshop," AIAA Journal of Aircraft, Vol. 45, No. 3, 2008, pp. 781798.

${ }^{3}$ Levy, D., Laflin, K., Tinoco, E., Vassberg, J., Mani, M., Rider, B., Wahls, C. R. R., Morrison, J., Broderson, O., Crippa, S., Mavriplis, D., and Murayama, M., "Summary of Data from the Fifth Computational Fluid Dynamics Drag Prediction Workshop," Journal of Aircraft, Vol. 51, No. 4, 2014, pp. 1194-1213. 263.

${ }^{4}$ Spalart, P. R., "Strategies for Turbulence Modelling and Simulation," International Journal of Heat and Fluid Flow, Vol. 21, 2000, pp. 252

${ }^{5}$ Simpson, R. L., “Juncture Flows,” Annual Review of Fluid Mechanics, Vol. 33, 2001, pp. 415-443.

${ }^{6}$ Gand, F., Deck, S., and Brunet, V., “Flow Dynamics Pas a Simplified Wing Body Junction,” Physics of Fluids, Vol. 22, No. 11, Nov. 2010, pp. 11511.

${ }^{7}$ Nichols, R. H. and Buning, P. G., "User's Manual for Overflow 2.2," http://overflow.larc.nasa.gov/home/ users-manual-for-overflow-2-2/, Accessed: 2017-03-15.

${ }^{8}$ Gentry Jr, C. L., Quinto, P., Gatlin, G., and Applin, Z., "The Langley 14- by 22-Foot Subsonic Tunnel: Description, Flow Characteristics, and Guide for Users," NASA TP-3008, September 1990.

${ }^{9}$ Barber, T. J., “ An Investigation of Strut-Wall Intersection Losses,” Journal of Aircraft, Vol. 15, No. 10, Oct. 2010, pp. 677-681.

${ }^{10}$ Roozeboom, N. H., Lee, H. C., Zilliac, G. G., and Pulliam, T. H., "Comparison of Experimental Surface and Flow Field Measurements to Computational Results of the Juncture Flow Model,” AIAA Paper 2016-1558, Jan. 2016.

${ }^{11}$ Rumsey, C., Neuhart, D., and Kegerise, M., “The NASA Juncture Flow Experiment: Goals, Progress, and Preliminary Testing," AIAA Paper 2016-1557, January 2016.

${ }^{12}$ Kegerise, M. A. and Neuhart, D. H., "Wind Tunnel Test of a Risk-Reduction Wing/Fuselage Model to Examine Juncture-Flow Phenomena," NASA TM-219348, November 2016.

${ }^{13}$ Campbell, R. L., "Efficient Viscous Design of Realistic Aircraft Configurations," AIAA Paper 1998-2539, June 1998.

${ }^{14}$ Chan, W. M., Gomez, R. J., Rogers, S. E., and Buning, P. G., "Best Practices in Overset theGrid Generation,” AIAA Paper 2002-3191, Jun. 2002.

${ }^{15}$ Roe, P. L., “Approximate Riemann Solvers, Parameter Vectors, and Difference Schemes,” J. Comp. Phys., Vol. 43, 1981, pp. 357-372.

${ }^{16}$ Allmaras, S. R., Johnson, F. T., and Spalart, P. R., "Modifications and Clarifications for the Implementation of the Spalart-Allmaras Turbulence Model,” ICCFD7 1902, July 2012.

${ }^{17}$ Meakin, R. L., "Object X-Rays for Cutting Holes in Composite Overset Structured Grids," AIAA Paper 2001-2537, June 2001.

${ }^{18}$ Nayani, S. N., Sellers, W., Tinetti, A. F., Brynildsen, S. E., and Walker, E. L., "Numerical Simulation of a Complete Low-Speed Wind Tunnel Circuit," AIAA Paper 2016-2117, January 2016.

${ }^{19}$ Rumsey, C. L., Carlson, J. R., Hannon, J. A., Jenkins, L. N., Bartram, S. M., Pulliam, T. H., and Lee, H. C., "Boundary Condition Study for the Juncture Flow Experiment in the NASA Langley 14x22-Foot Subsonic Wind Tunnel," Aiaa paper, Jun. 2017.

20 “User's Manual, Tecplot 360 EX 2017 Release 1," http://download.tecplot.com/360/current/360_users_manual. pdf, Accessed: 2017-03-15.

${ }^{21}$ Devenport, W. J. and Simpson, R. L., "Time-Dependent and Time-Averaged Turbulence Structure Near the Nose of a Wing-Body Junction," Journal of Fluid Mechanics, Vol. 210, 1990, pp. 23-55. 


\section{Appendix}

\section{Configuration 1: F6 (port) wing}

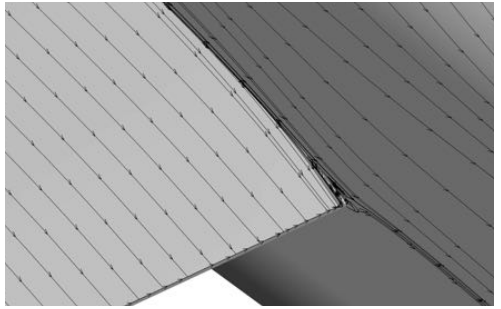

(a) CFD-Air, $\alpha=-10.0^{\circ}$

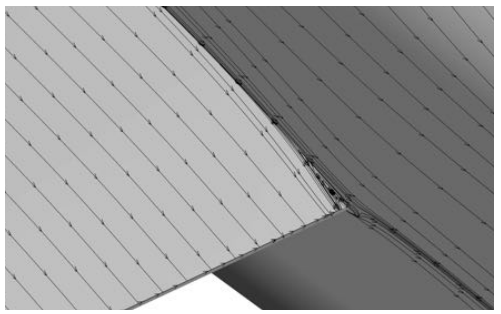

(d) CFD-Air, $\alpha=-7.5^{\circ}$

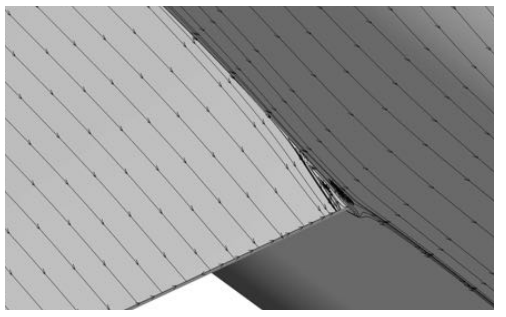

(g) CFD-Air, $\alpha=-5.0^{\circ}$

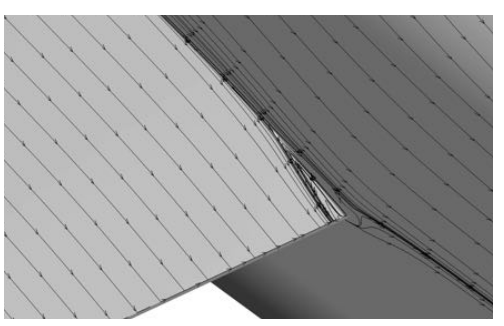

(j) CFD-Air, $\alpha=-2.5^{\circ}$

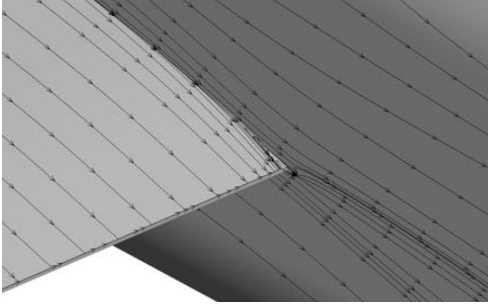

(b) CFD-WT, $\alpha=-10.0^{\circ}$

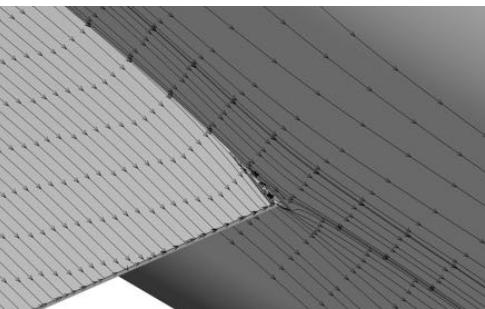

(e) CFD-WT, $\alpha=-7.5^{\circ}$

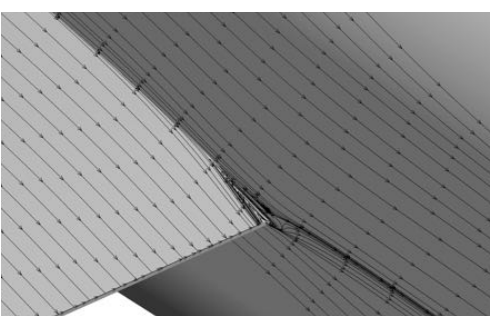

(h) CFD-WT, $\alpha=-5.0^{\circ}$

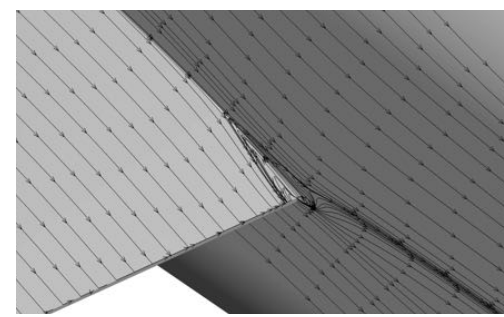

(k) CFD-WT, $\alpha=-2.5^{\circ}$

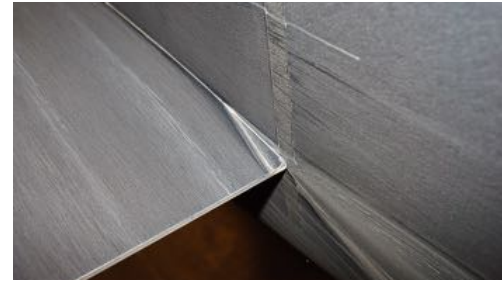

(c) Experiment, $\alpha=-10.0^{\circ}$

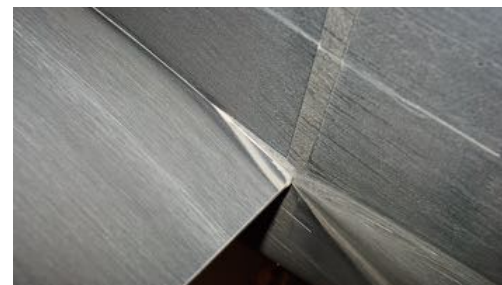

(f) Experiment, $\alpha=-7.5^{\circ}$

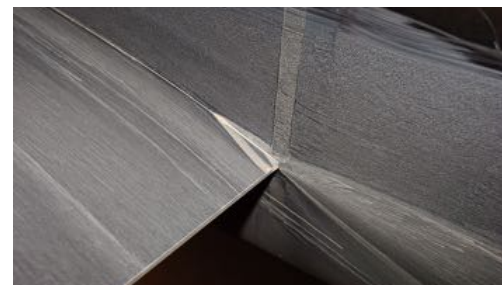

(i) Experiment, $\alpha=-5.0^{\circ}$

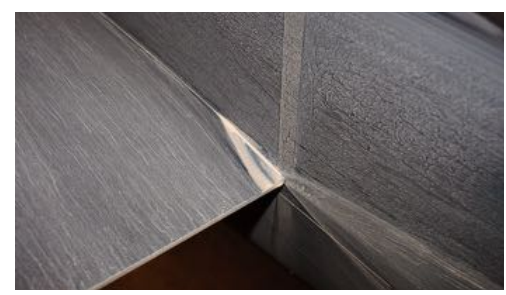

(1) Experiment, $\alpha=-2.5^{\circ}$

Figure 18. Side-of-body separation versus model angle of attack, Configuration 1 F6 port wing, surface streamlines and oil-flow, $\alpha=$ $-10.0^{\circ}$ to $-2.5^{\circ}$. 


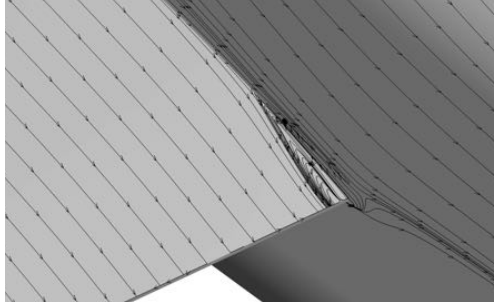

(a) CFD-Air, $\alpha=0.0^{\circ}$

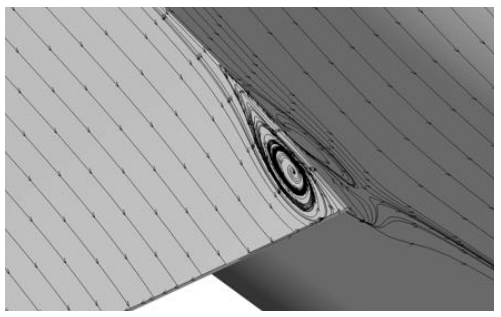

(d) CFD-Air, $\alpha=2.5^{\circ}$

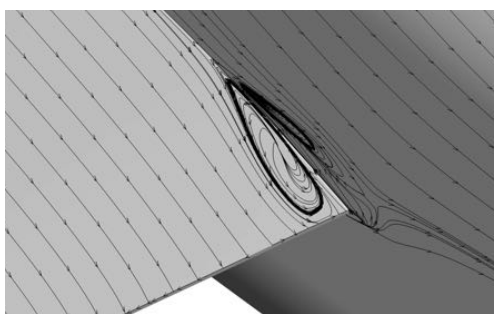

(g) CFD-Air, $\alpha=5.0^{\circ}$

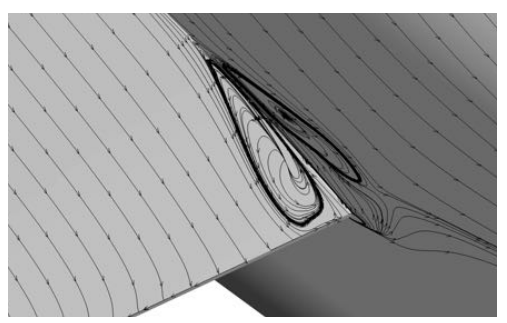

(j) CFD-Air, $\alpha=7.5^{\circ}$

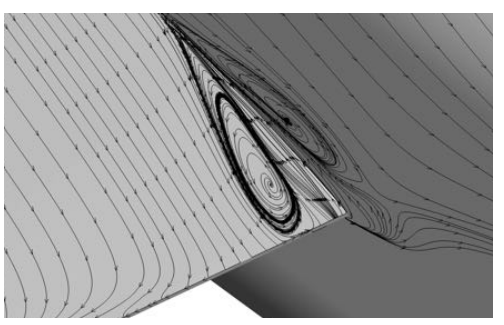

(m) CFD-Air, $\alpha=10.0^{\circ}$

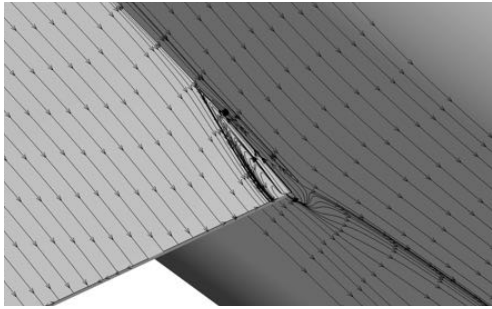

(b) CFD-WT, $\alpha=0.0^{\circ}$

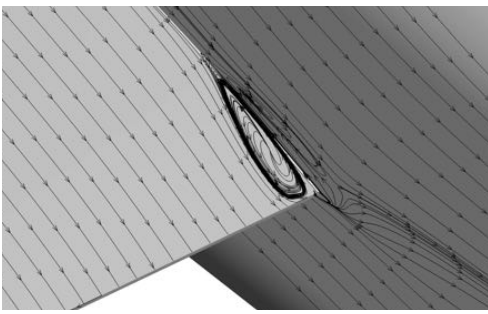

(e) CFD-WT, $\alpha=2.5^{\circ}$

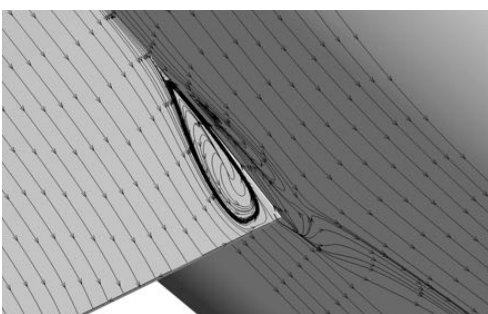

(h) CFD-WT, $\alpha=5.0^{\circ}$

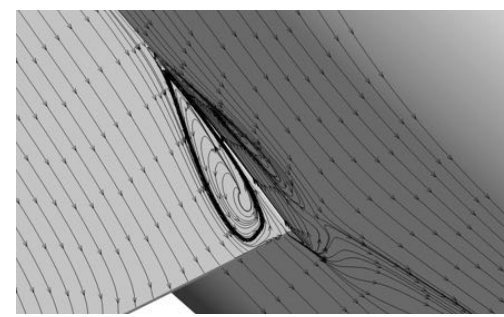

(k) CFD-WT, $\alpha=7.5^{\circ}$

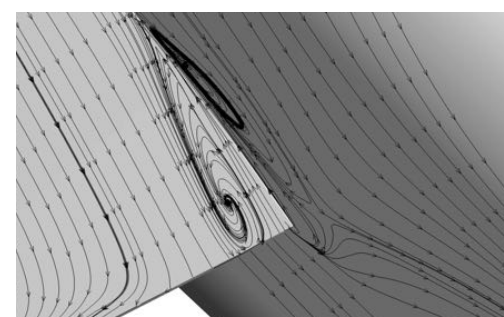

(n) CFD-WT, $\alpha=10.0^{\circ}$

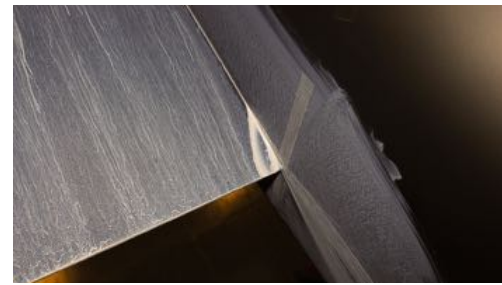

(c) Experiment, $\alpha=0.0^{\circ}$

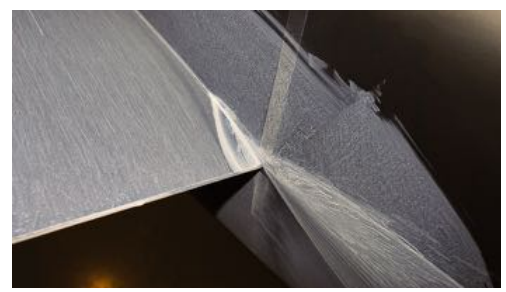

(f) Experiment, $\alpha=2.5^{\circ}$

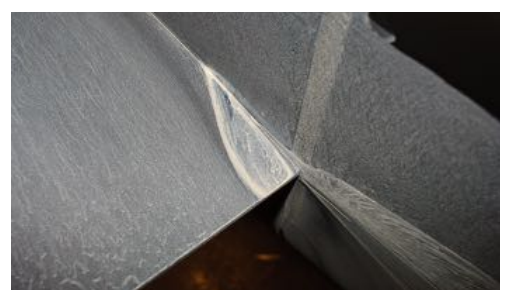

(i) Experiment, $\alpha=5.0^{\circ}$

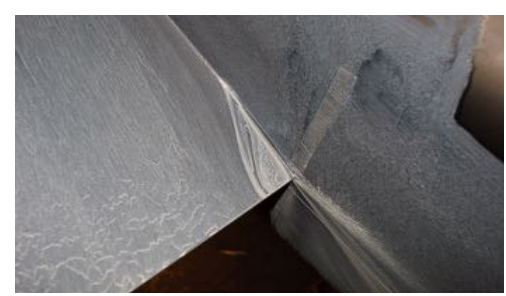

(1) Experiment, $\alpha=7.5^{\circ}$

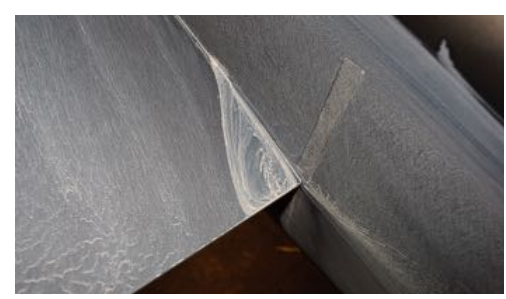

(o) Experiment, $\alpha=10.0^{\circ}$

Figure 19. Side-of-body separation versus model angle of attack, Configuration 1 F6 port wing, surface streamlines and oil-flow, $\alpha=0.0^{\circ}$ to $10.0^{\circ}$. 
Configuration 1: F6 with leading edge horn (starboard) wing

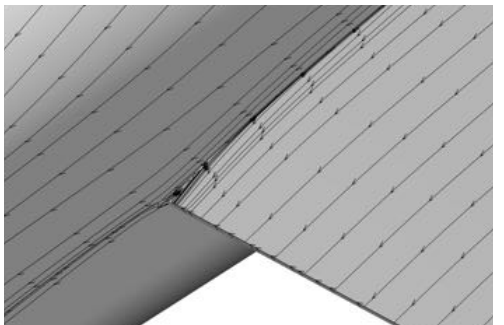

(a) CFD-Air, $\alpha=-10.0^{\circ}$

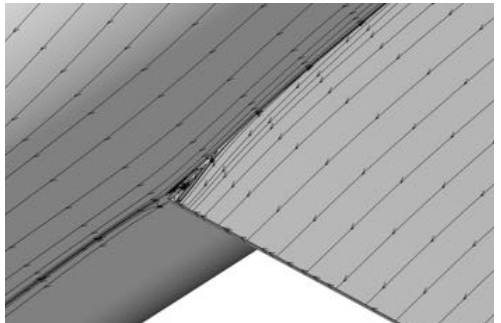

(d) CFD-Air, $\alpha=-7.5^{\circ}$

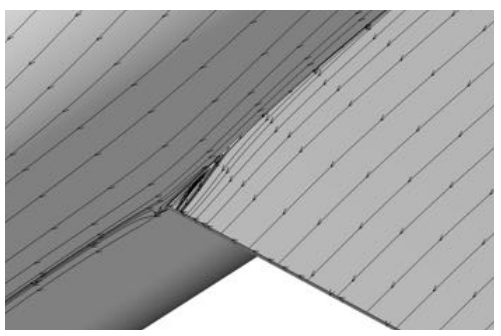

(g) CFD-Air, $\alpha=-5.0^{\circ}$

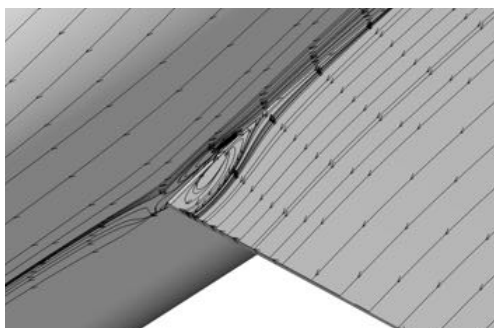

(j) CFD-Air, $\alpha=-2.5^{\circ}$

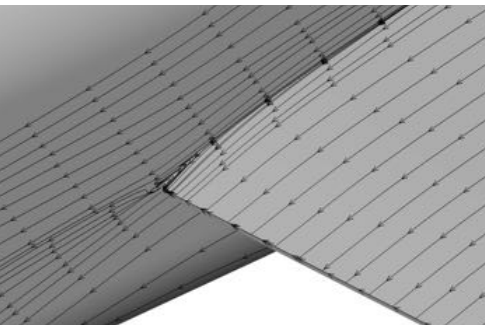

(b) CFD-WT, $\alpha=-10.0^{\circ}$

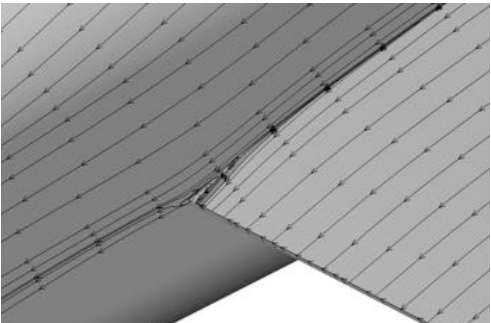

(e) CFD-WT, $\alpha=-7.5^{\circ}$

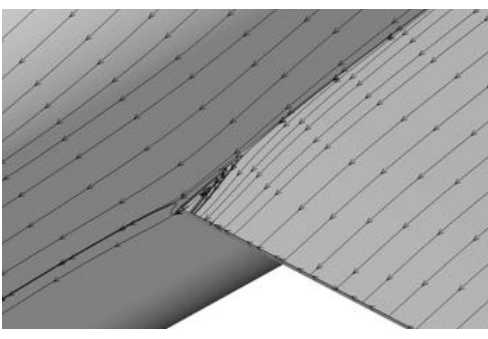

(h) CFD-WT, $\alpha=-5.0^{\circ}$

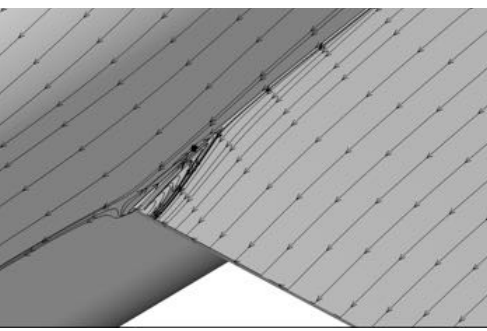

(k) CFD-WT, $\alpha=-2.5^{\circ}$

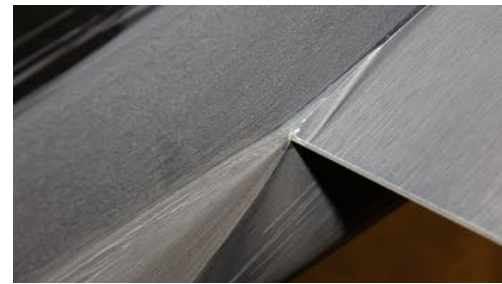

(c) Experiment, $\alpha=-10.0^{\circ}$

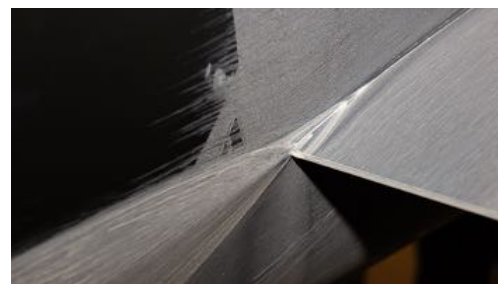

(f) Experiment, $\alpha=-7.5^{\circ}$

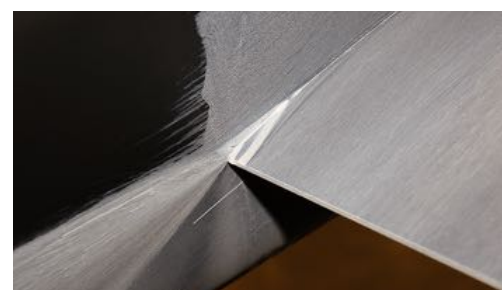

(i) Experiment, $\alpha=-5.0^{\circ}$

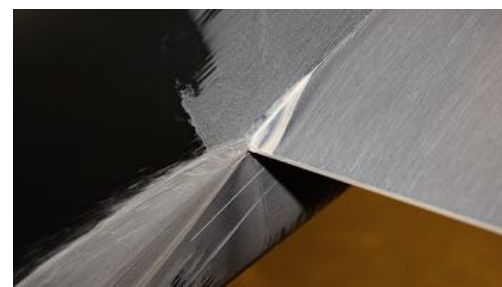

(l) Experiment, $\alpha=-2.5^{\circ}$

Figure 20. Side-of-body separation versus model angle of attack, Configuration 1 F6 w/horn starboard wing, surface streamlines and oil-flow, $\alpha=-10.0^{\circ}$ to $-2.5^{\circ}$. 


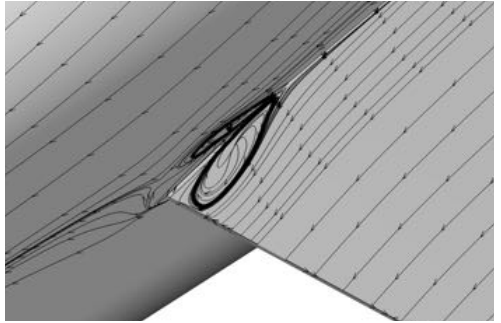

(a) CFD-Air, $\alpha=0.0^{\circ}$

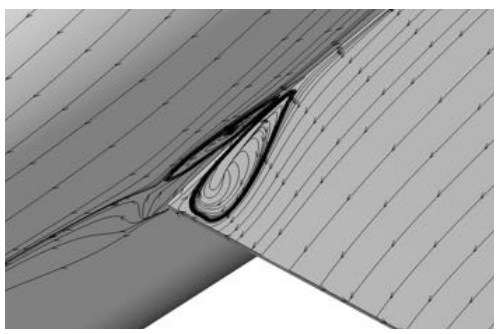

(d) CFD-Air, $\alpha=2.5^{\circ}$

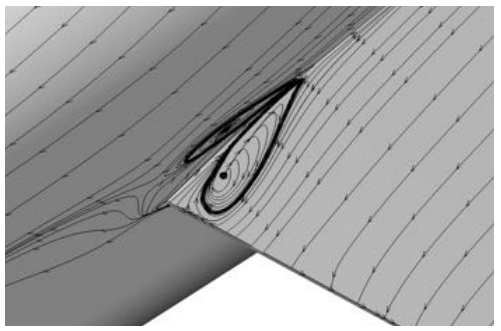

(g) CFD-Air, $\alpha=5.0^{\circ}$

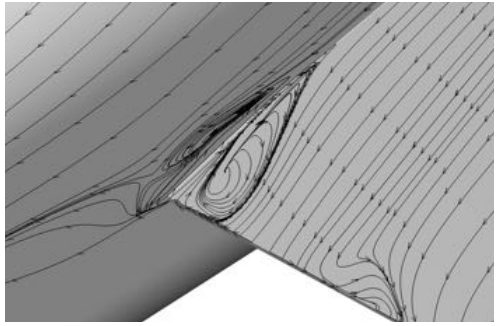

(j) CFD-Air, $\alpha=7.5^{\circ}$

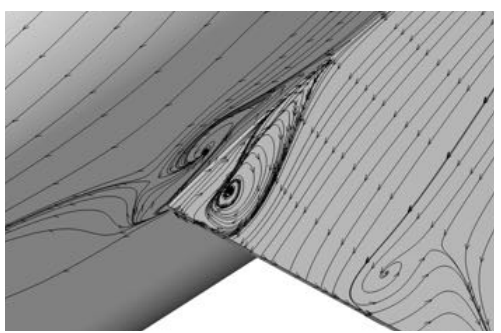

(m) CFD-Air, $\alpha=10.0^{\circ}$

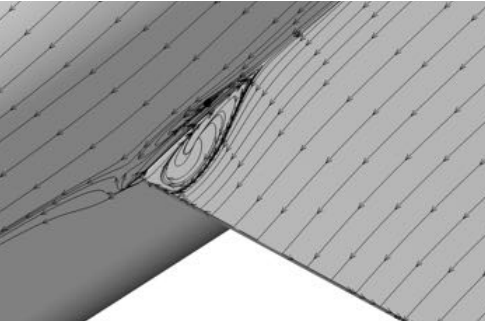

(b) CFD-WT, $\alpha=0.0^{\circ}$

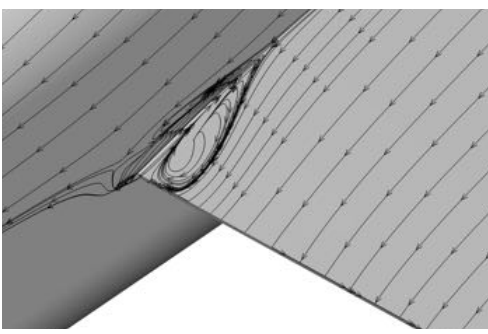

(e) CFD-WT, $\alpha=2.5^{\circ}$

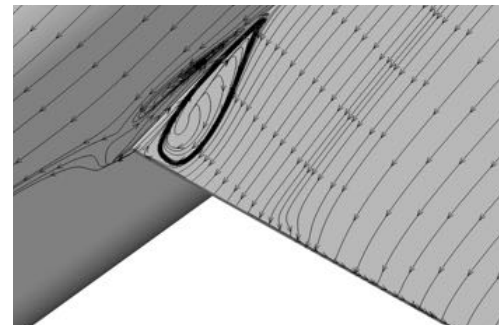

(h) CFD-WT, $\alpha=5.0^{\circ}$

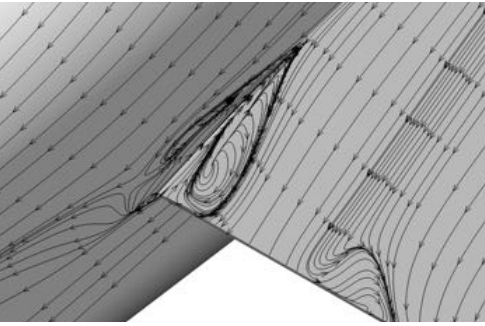

(k) CFD-WT, $\alpha=7.5^{\circ}$

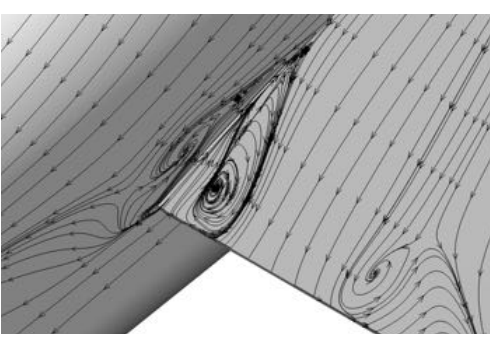

(n) CFD-WT, $\alpha=10.0^{\circ}$

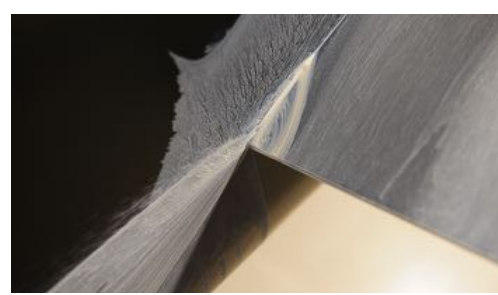

(c) Experiment, $\alpha=0.0^{\circ}$

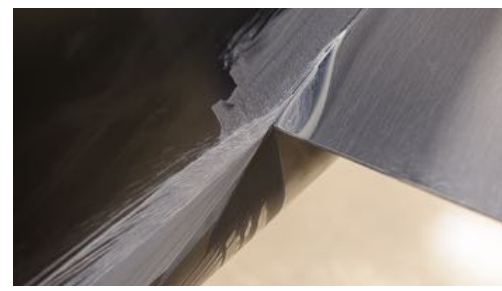

(f) Experiment, $\alpha=2.5^{\circ}$

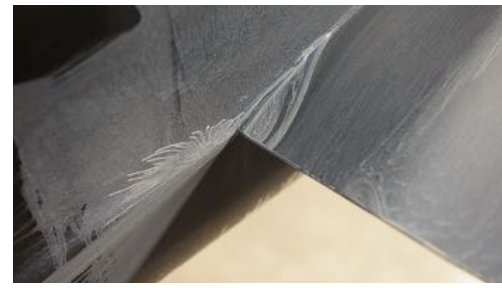

(i) Experiment, $\alpha=5.0^{\circ}$

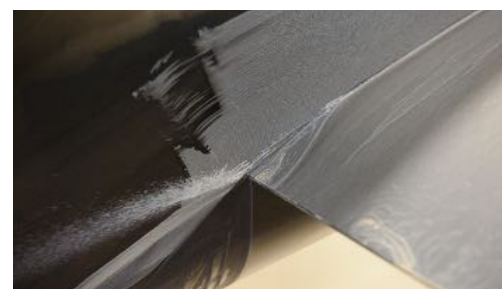

(1) Experiment, $\alpha=7.5^{\circ}$

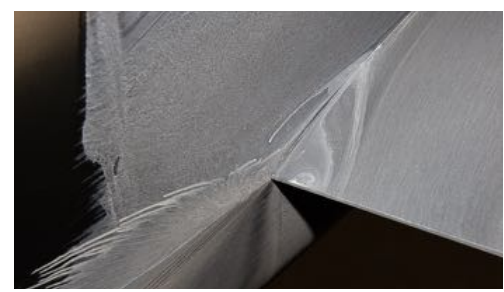

(o) Experiment, $\alpha=10.0^{\circ}$

Figure 21. Side-of-body separation versus model angle of attack, Configuration 1 F6 w/horn starboard wing,surface streamlines and oil-flow, $\alpha=0.0^{\circ}$ to $10.0^{\circ}$. 
Configuration 1: F6 leading edge (port) wing

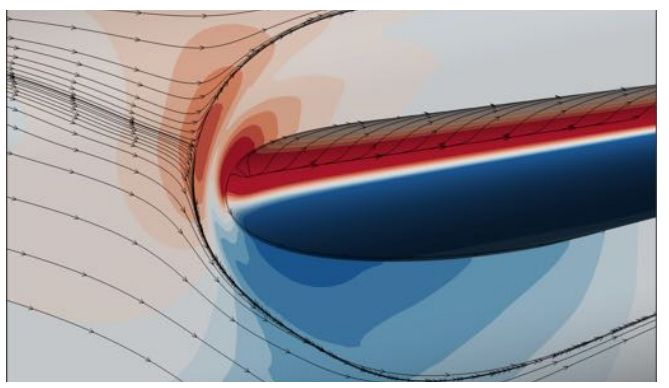

(a) CFD-WT, $\alpha=-10.0^{\circ}$

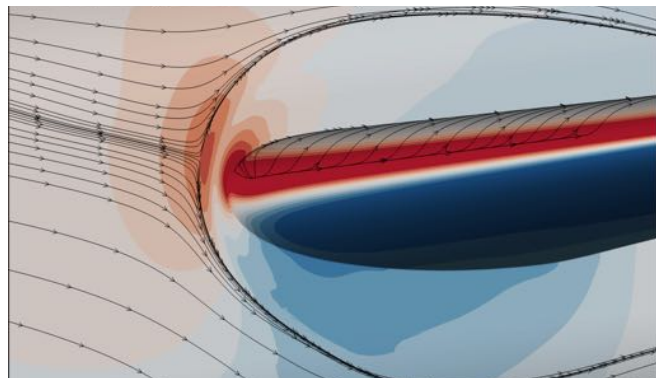

(c) CFD-WT, $\alpha=-7.5^{\circ}$

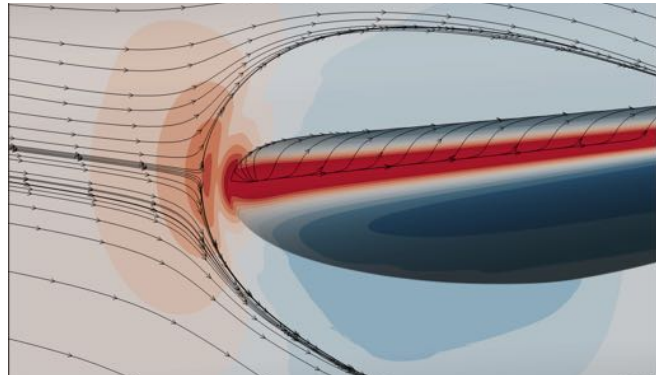

(e) CFD-WT, $\alpha=-5.0^{\circ}$

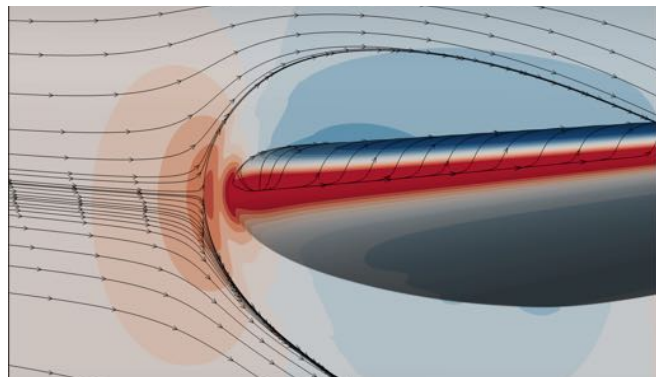

(g) CFD-WT, $\alpha=-2.5^{\circ}$

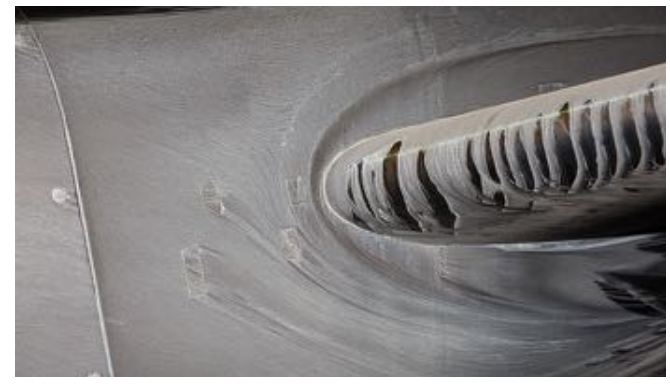

(b) Experiment, $\alpha=-10.0^{\circ}$

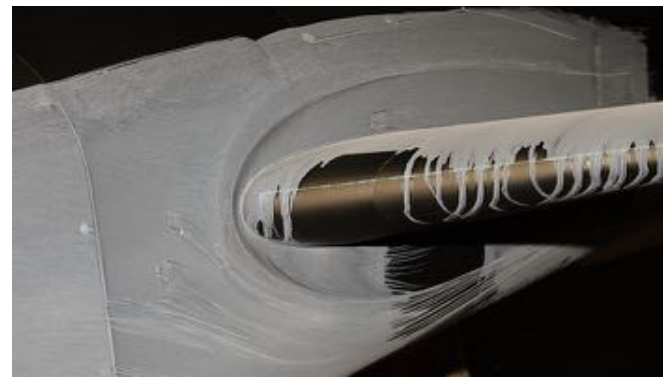

(d) Experiment, $\alpha=-7.5^{\circ}$

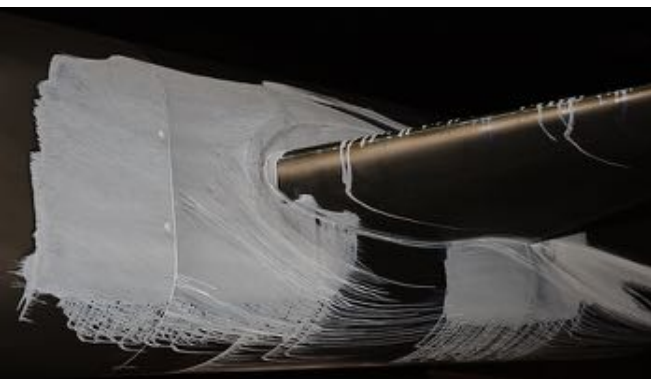

(f) Experiment, $\alpha=-5.0^{\circ}$

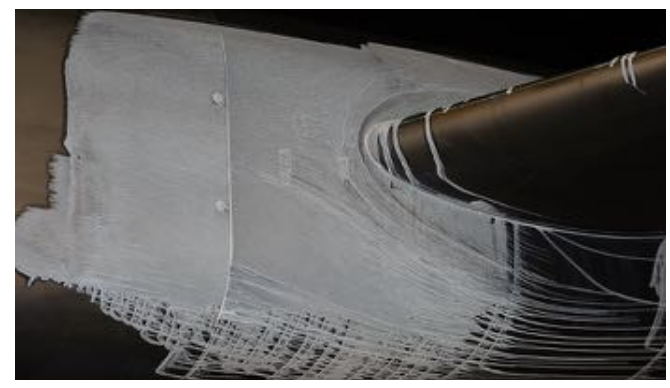

(h) Experiment, $\alpha=-2.5^{\circ}$

Figure 22. Leading-edge versus model angle of attack, Configuration $1 \mathrm{~F} 6$ port wing, surface streamlines and oil-flow, $\alpha=-10.0^{\circ}$ to $-2.5^{\circ}$. 


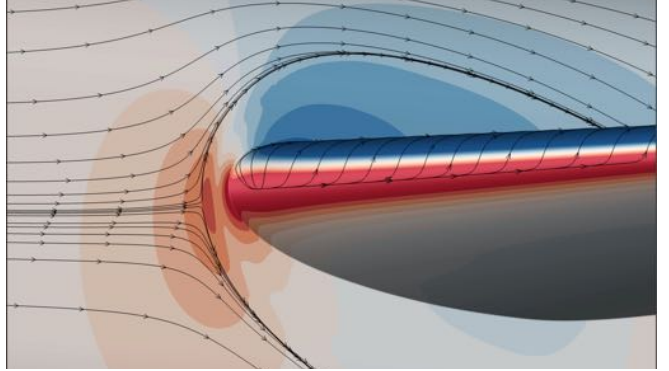

(a) CFD-WT, $\alpha=0.0^{\circ}$

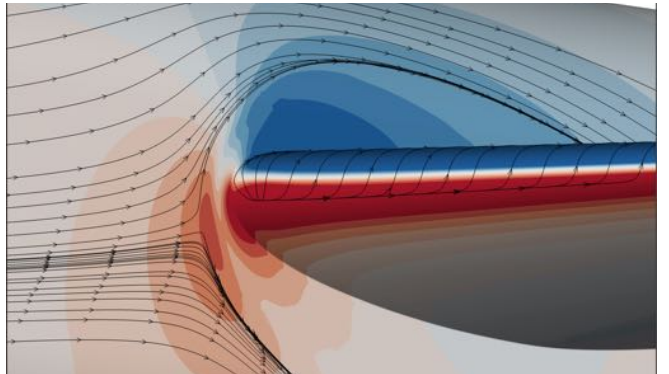

(c) CFD-WT, $\alpha=2.5^{\circ}$

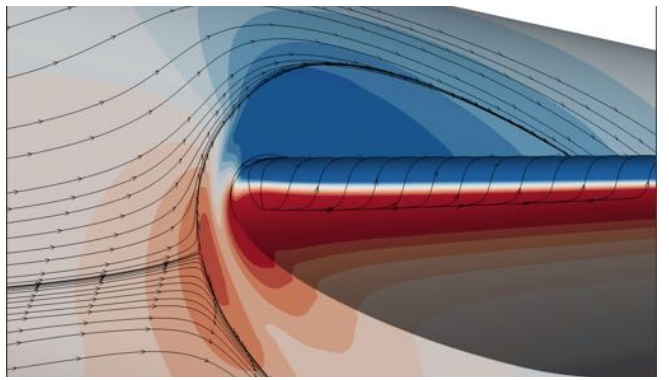

(e) CFD-WT, $\alpha=5.0^{\circ}$

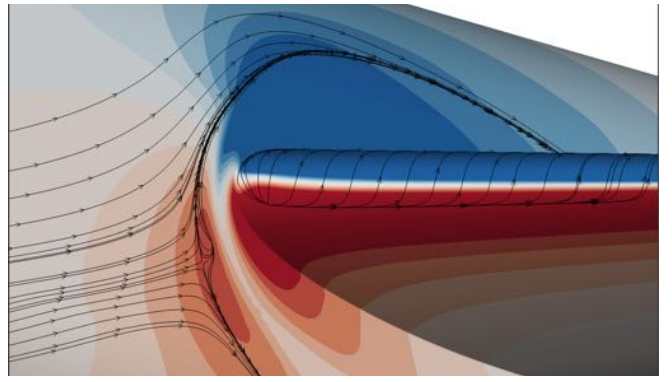

(g) CFD-WT, $\alpha=7.5^{\circ}$

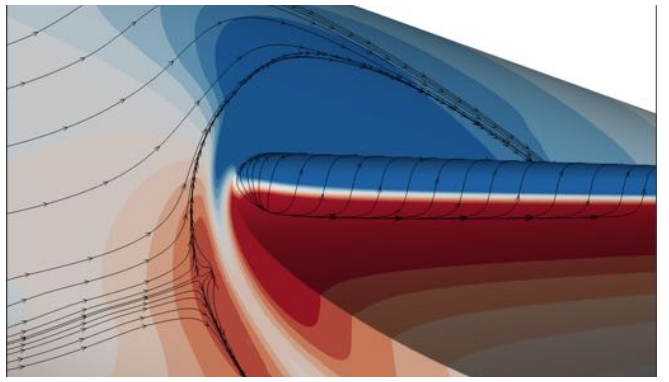

(i) CFD-WT, $\alpha=10.0^{\circ}$

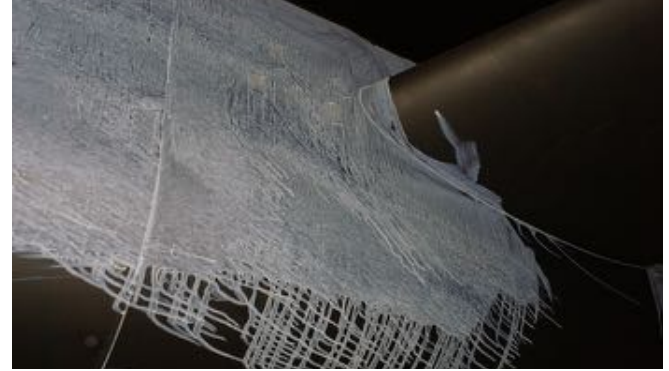

(b) Experiment, $\alpha=0.0^{\circ}$

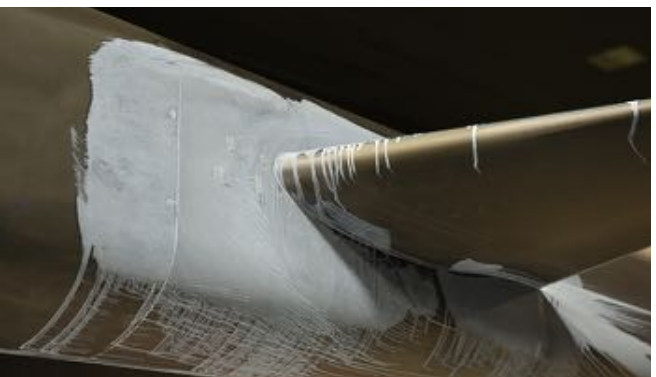

(d) Experiment, $\alpha=2.5^{\circ}$

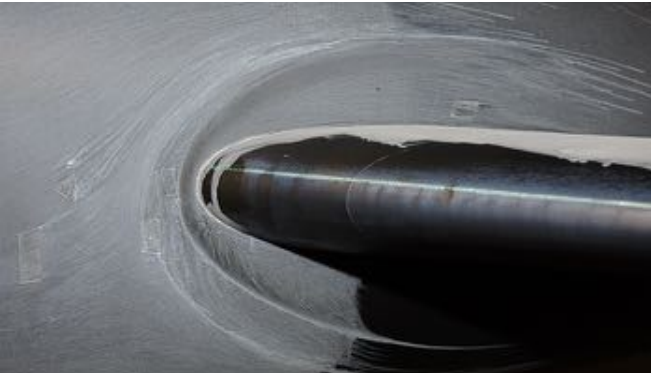

(f) Experiment, $\alpha=5.0^{\circ}$

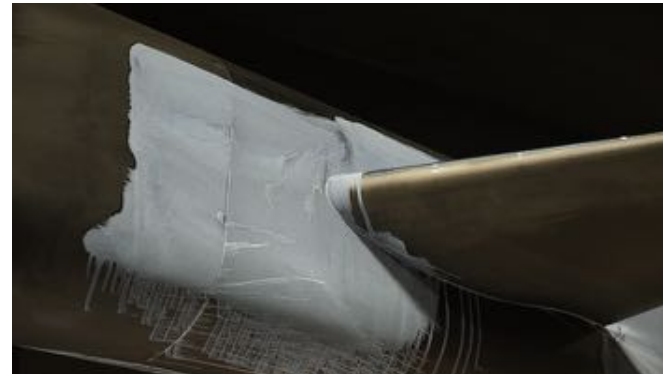

(h) Experiment, $\alpha=7.5^{\circ}$

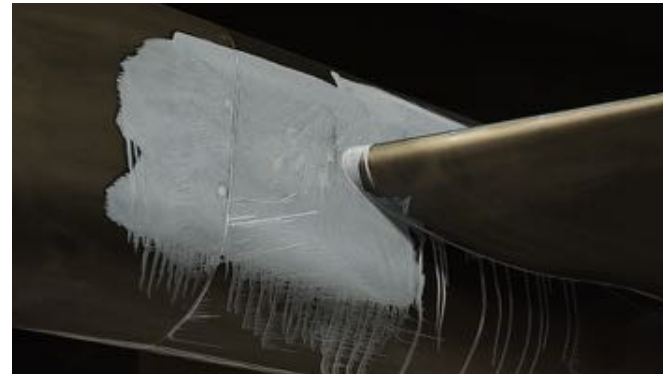

(j) Experiment, $\alpha=10.0^{\circ}$

Figure 23. Leading-edge versus model angle of attack, Configuration 1 F6 port wing, surface streamlines and oil-flow, $\alpha=0.0^{\circ}$ to $10.0^{\circ}$. 
Configuration 1: F6 leading edge with horn (starboard) wing

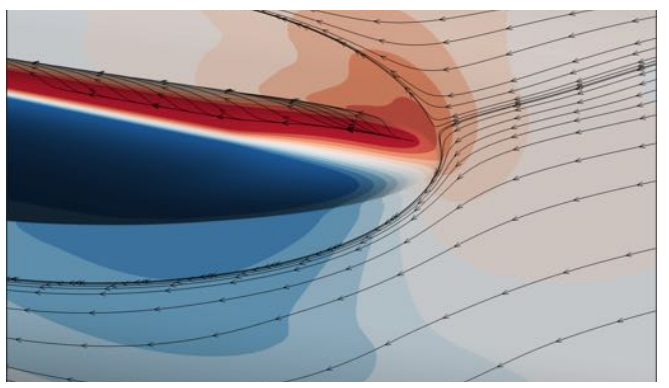

(a) CFD-WT, $\alpha=-10.0^{\circ}$

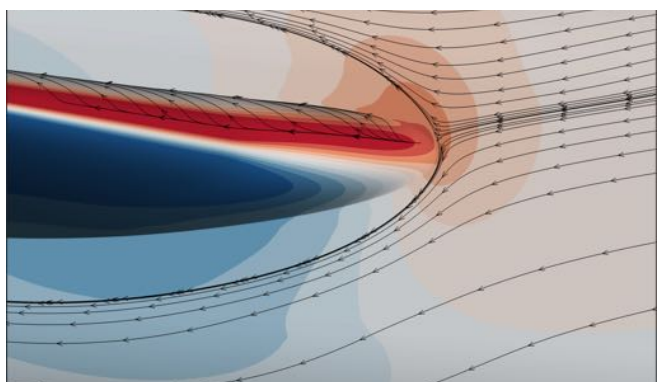

(c) CFD-WT, $\alpha=-7.5^{\circ}$

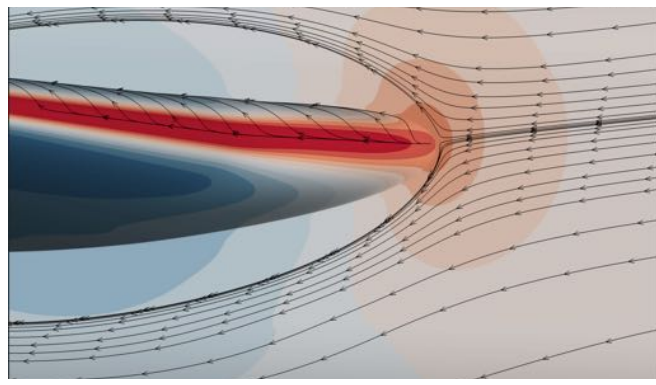

(e) CFD-WT, $\alpha=-5.0^{\circ}$

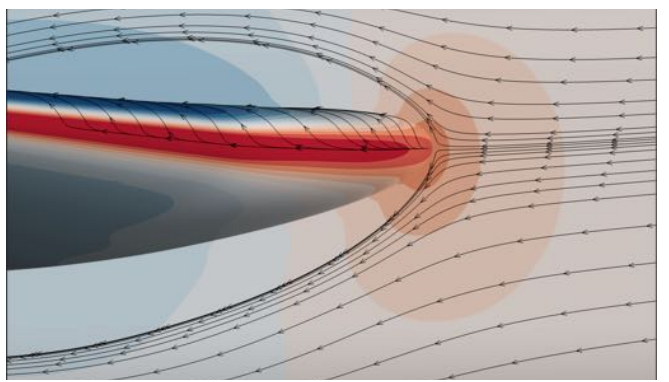

(g) CFD-WT, $\alpha=-2.5^{\circ}$

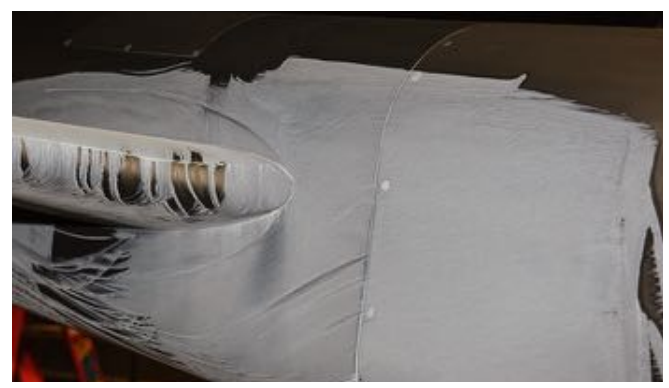

(b) Experiment, $\alpha=-10.0^{\circ}$

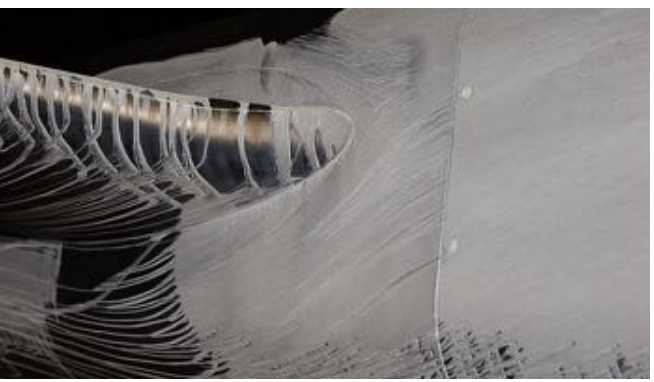

(d) Experiment, $\alpha=-7.5^{\circ}$

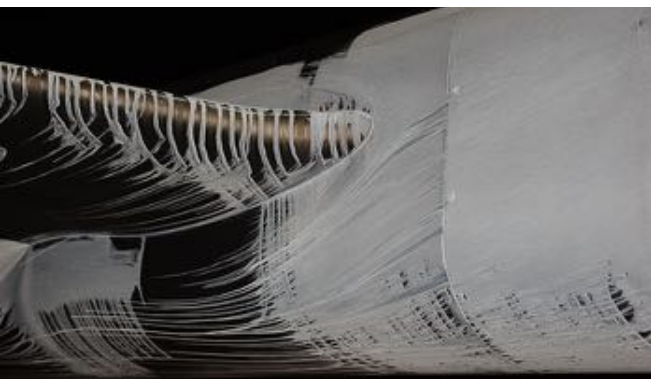

(f) Experiment, $\alpha=-5.0^{\circ}$

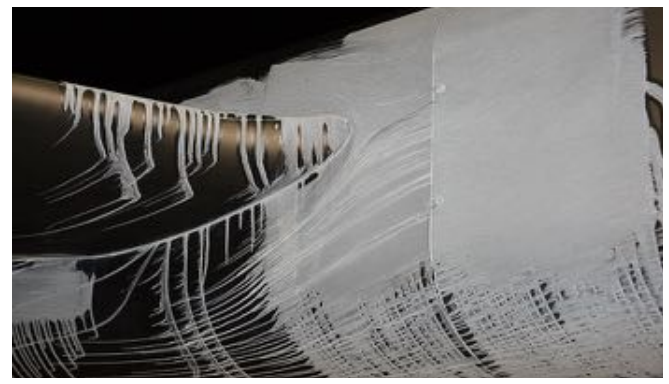

(h) Experiment, $\alpha=-2.5^{\circ}$

Figure 24. Leading-edge versus model angle of attack, Configuration 1 F6 w/horn starboard wing, surface streamlines and oil-flow, $\alpha=$ $-10.0^{\circ}$ to $2.5^{\circ}$. 


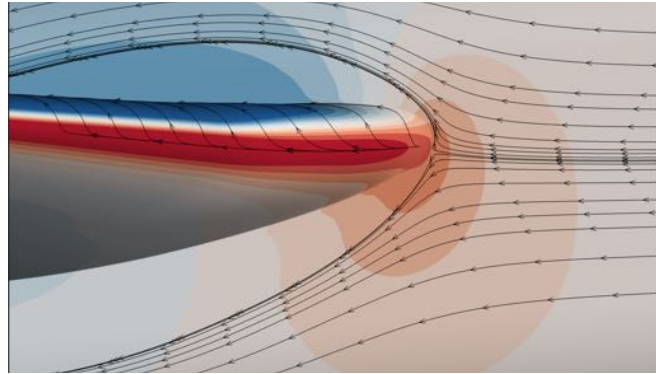

(a) CFD-WT, $\alpha=0.0^{\circ}$

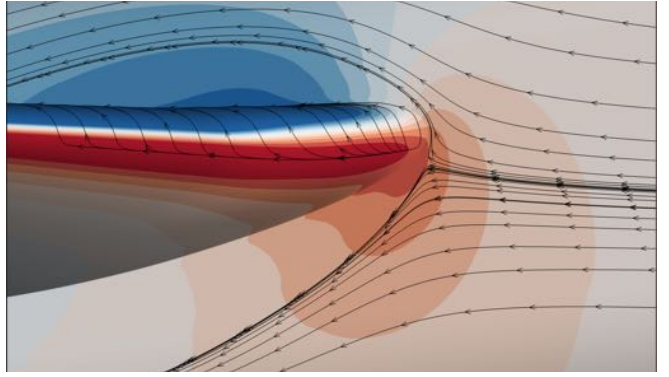

(c) CFD-WT, $\alpha=2.5^{\circ}$

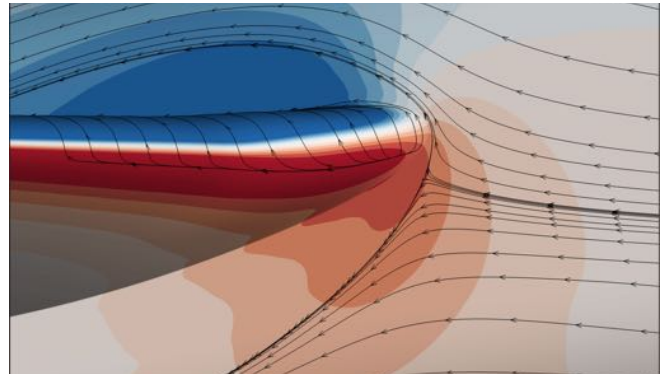

(e) CFD-WT, $\alpha=5.0^{\circ}$

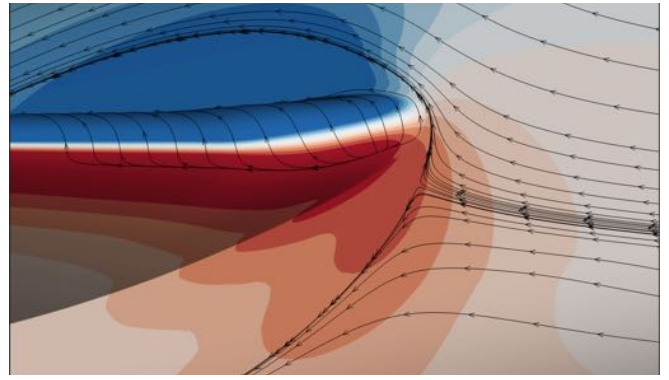

(g) CFD-WT, $\alpha=7.5^{\circ}$

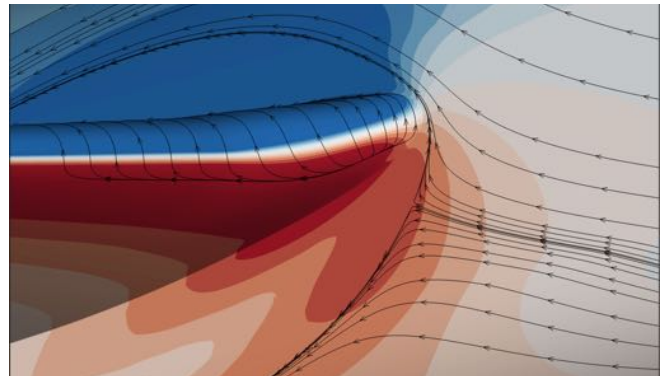

(i) CFD-WT, $\alpha=10.0^{\circ}$

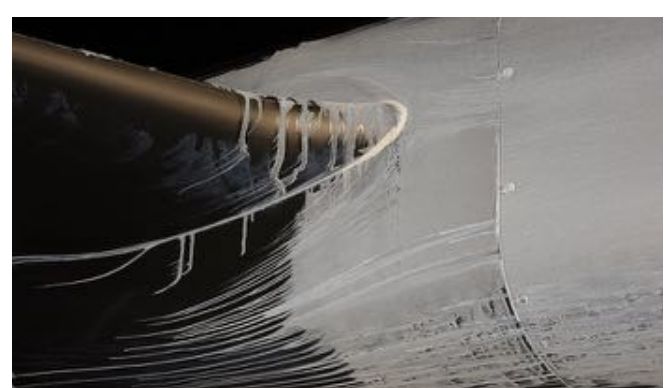

(b) Experiment, $\alpha=0.0^{\circ}$

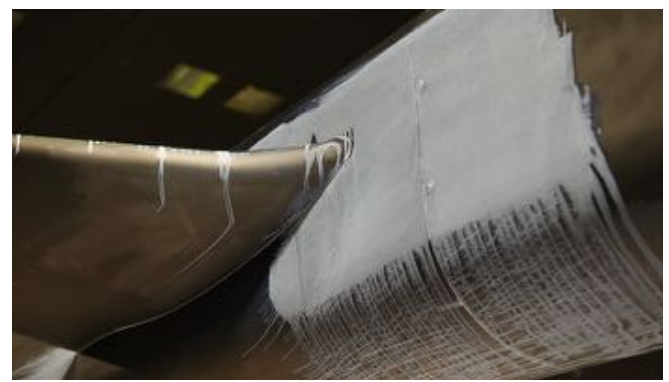

(d) Experiment, $\alpha=2.5^{\circ}$

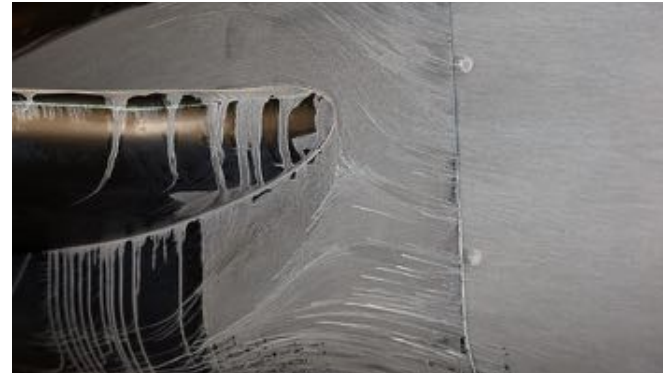

(f) Experiment, $\alpha=5.0^{\circ}$

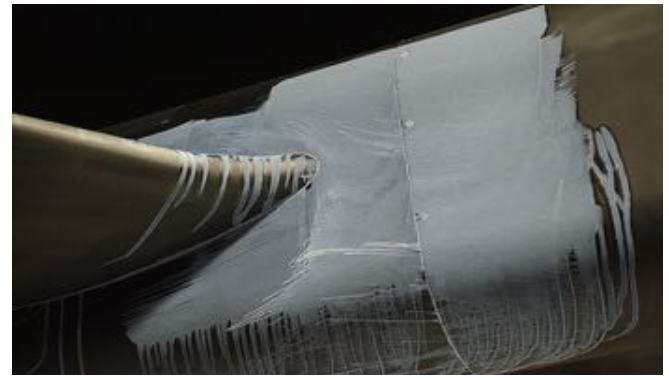

(h) Experiment, $\alpha=7.5^{\circ}$

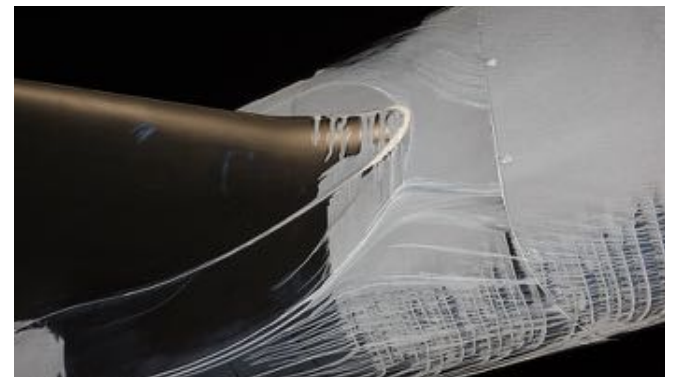

(j) Experiment, $\alpha=10.0^{\circ}$

Figure 25. Leading-edge versus model angle of attack, Configuration 1 F6 w/horn starboard wing, surface streamlines and oil-flow, $\alpha=$ $0.0^{\circ}$ to $10.0^{\circ}$. 
Configuration 2: NACA 0015 (port) wing

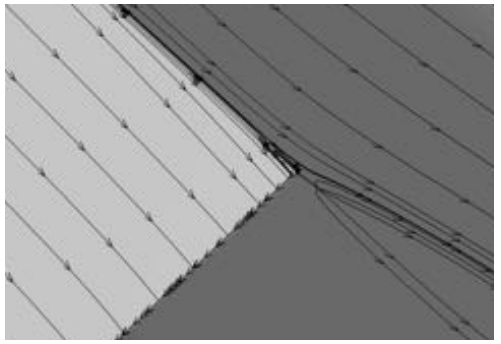

(a) CFD-Air, $\alpha=0.0^{\circ}$

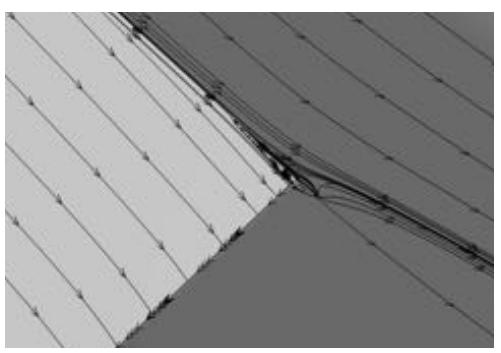

(d) CFD-Air, $\alpha=2.5^{\circ}$

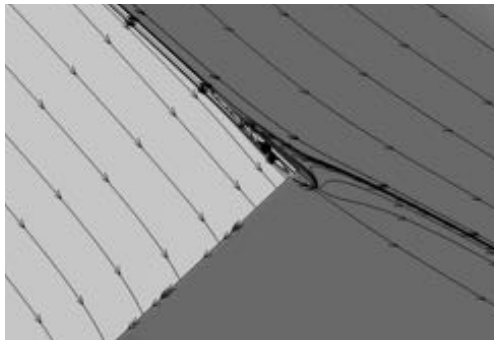

(g) CFD-Air, $\alpha=5.0^{\circ}$

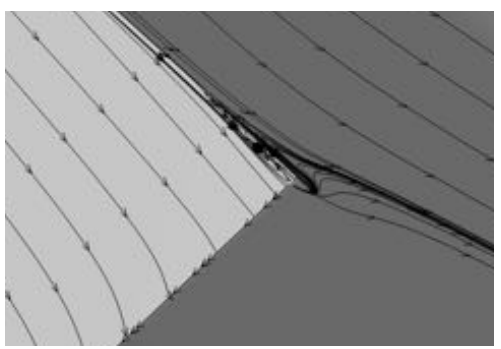

(j) CFD-Air, $\alpha=7.5^{\circ}$

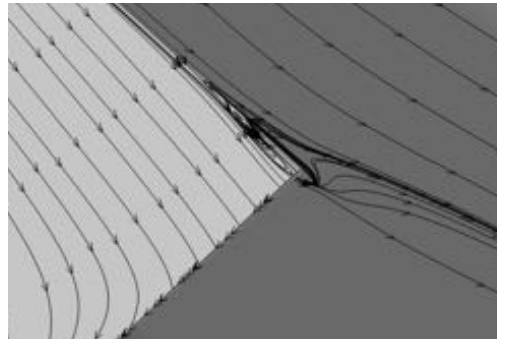

(m) CFD-Air, $\alpha=10.0^{\circ}$

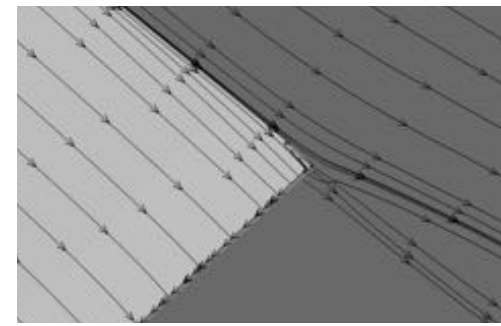

(b) CFD-WT, $\alpha=0.0^{\circ}$

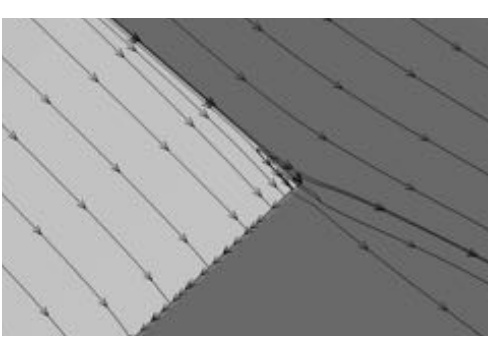

(e) CFD-WT, $\alpha=2.5^{\circ}$

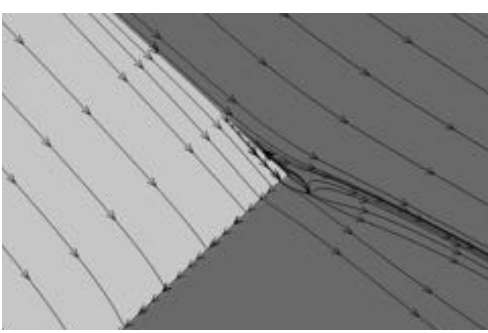

(h) CFD-WT, $\alpha=5.0^{\circ}$

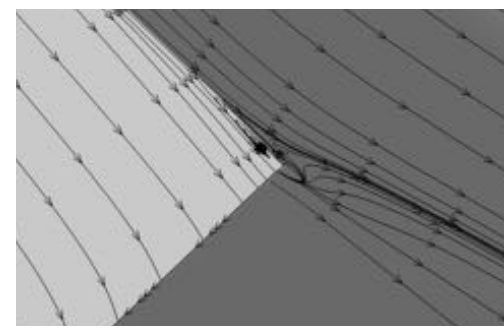

(k) CFD-WT, $\alpha=7.5^{\circ}$

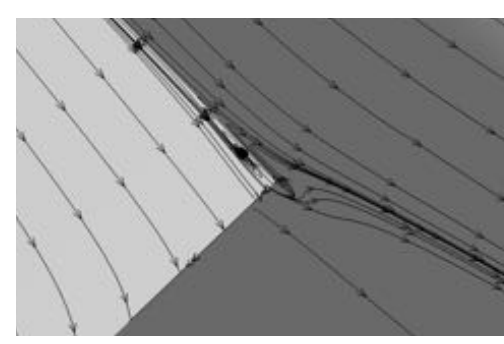

(n) CFD-WT, $\alpha=10.0^{\circ}$

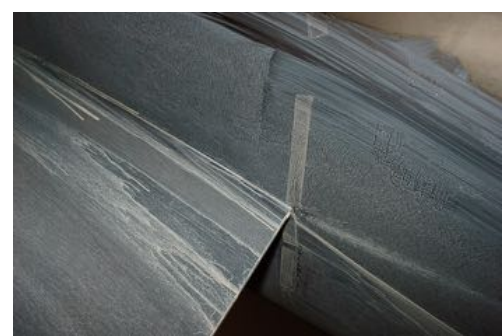

(c) Experiment, $\alpha=0.0^{\circ}$

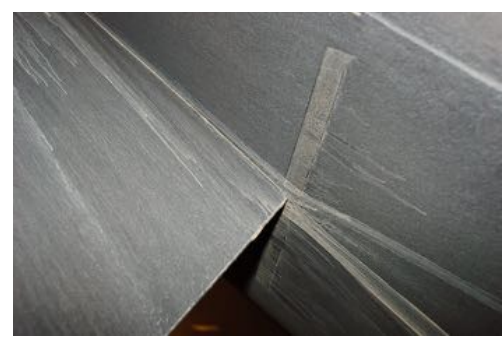

(f) Experiment, $\alpha=2.5^{\circ}$

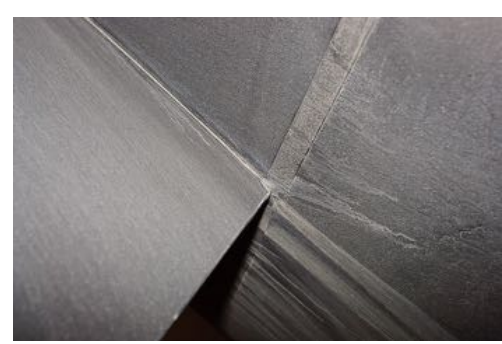

(i) Experiment, $\alpha=5.0^{\circ}$

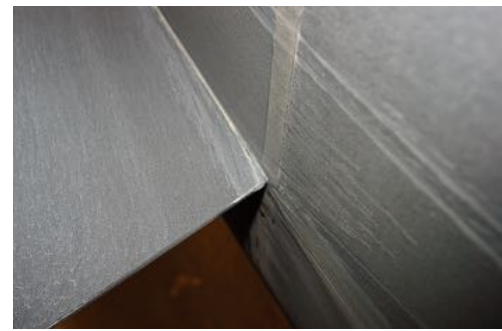

(l) Experiment, $\alpha=7.5^{\circ}$

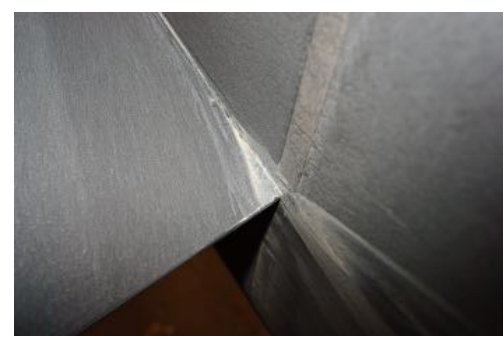

(o) Experiment, $\alpha=10.0^{\circ}$

Figure 26. Side-of-body separation versus model angle of attack, Configuration 2 NACA 0015 port wing, surface streamlines and oil-flow, $\alpha=0.0^{\circ}$ to $10.0^{\circ}$. 
Configuration 2: NACA $0015 \bmod$ (starboard) wing

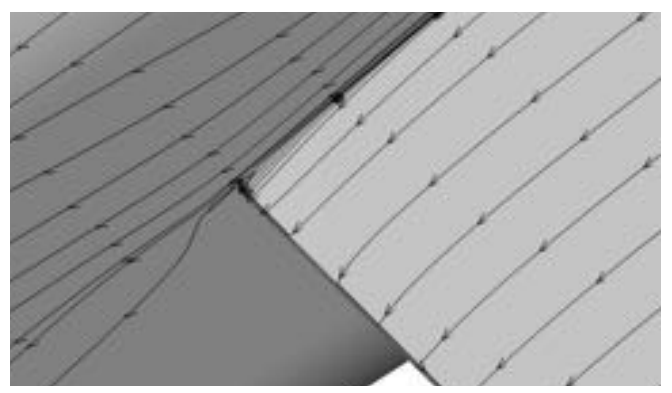

(a) CFD-Air, $\alpha=-10.0^{\circ}$

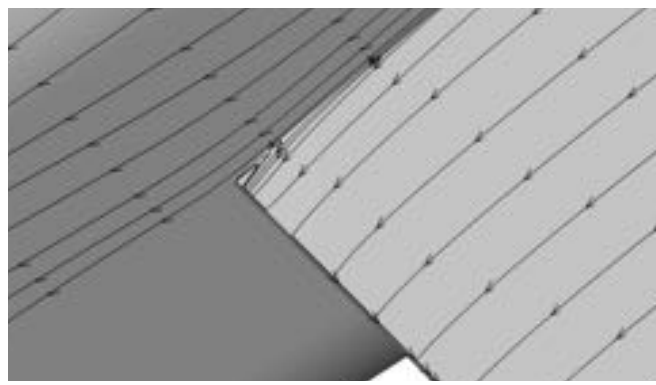

(c) CFD-Air, $\alpha=-7.5^{\circ}$

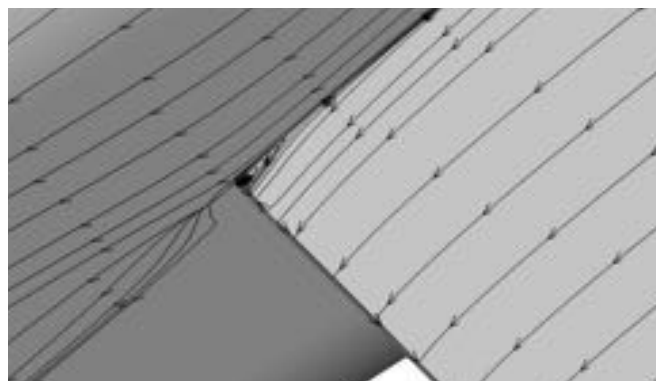

(e) CFD-Air, $\alpha=-5.0^{\circ}$

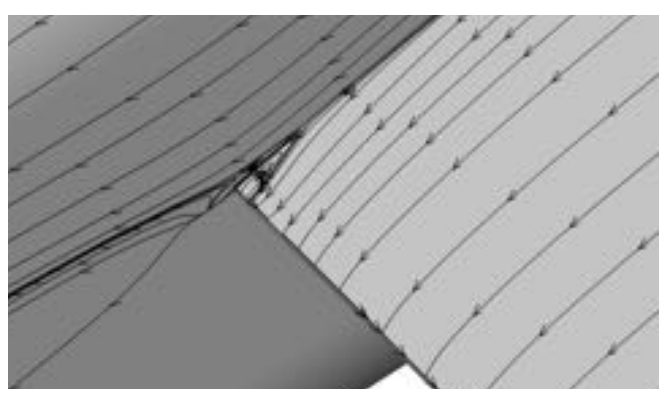

(g) CFD-Air, $\alpha=-2.5^{\circ}$

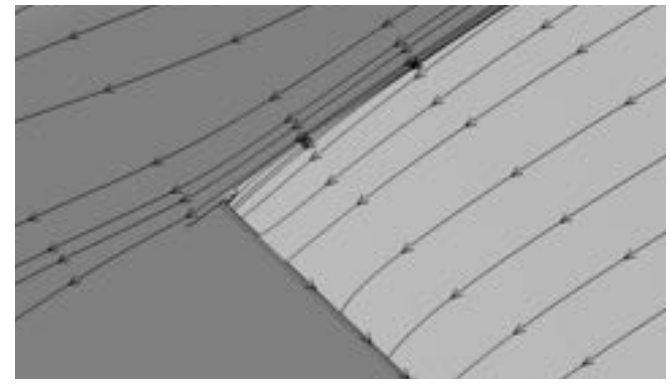

(b) CFD-WT, $\alpha=-10.0^{\circ}$

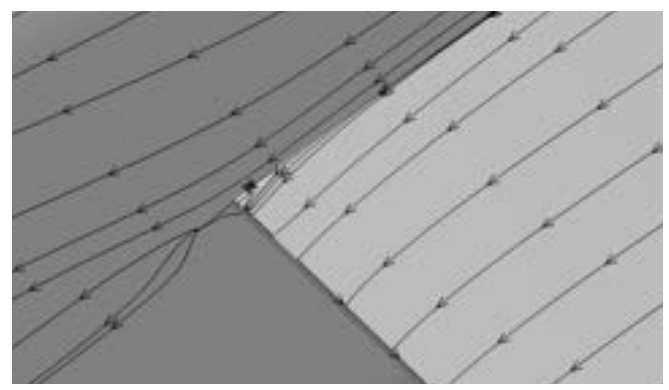

(d) CFD-WT, $\alpha=-7.5^{\circ}$

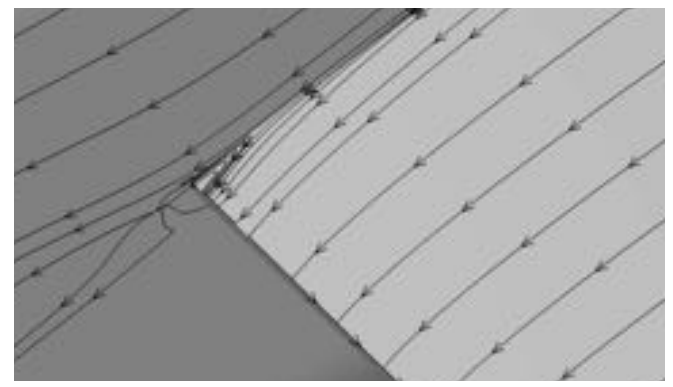

(f) CFD-WT, $\alpha=-5.0^{\circ}$

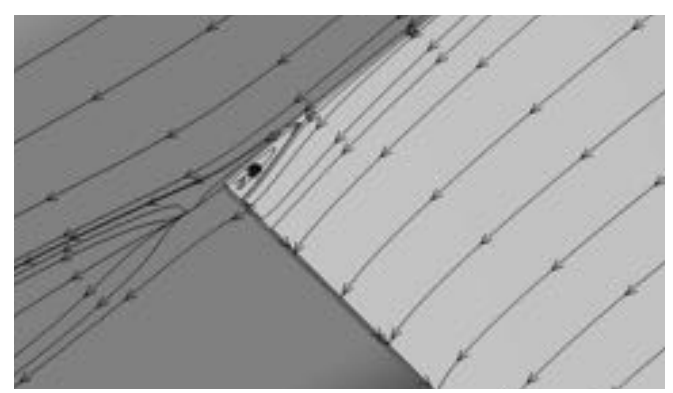

(h) CFD-WT, $\alpha=-2.5^{\circ}$

Figure 27. Side-of-body separation versus model angle of attack, Configuration 2 NACA 0015mod starboard wing, surface streamlines, $\alpha=$ $-10.0^{\circ}$ to $-2.5^{\circ}$. 


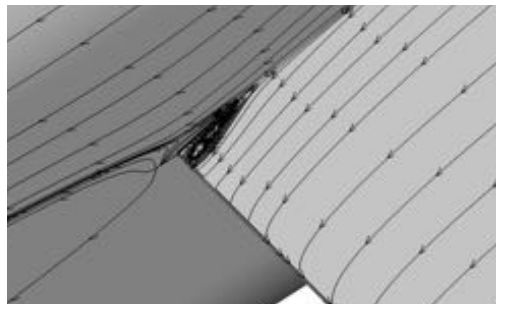

(a) CFD-Air, $\alpha=0.0^{\circ}$

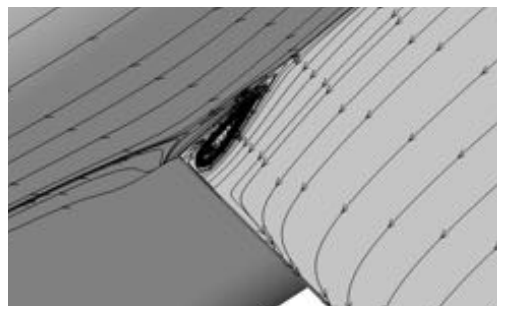

(d) CFD-Air, $\alpha=2.5^{\circ}$

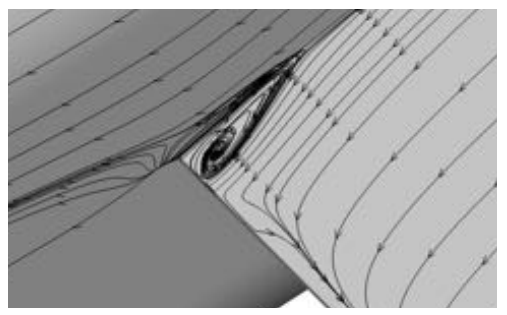

(g) CFD-Air, $\alpha=5.0^{\circ}$

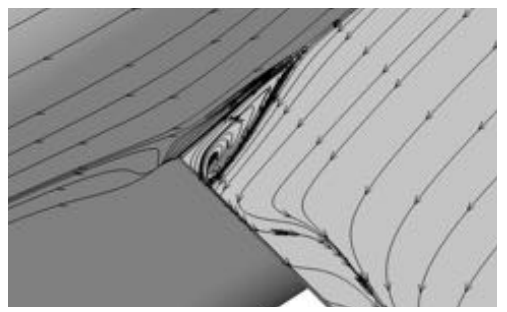

(j) CFD-Air, $\alpha=7.5^{\circ}$

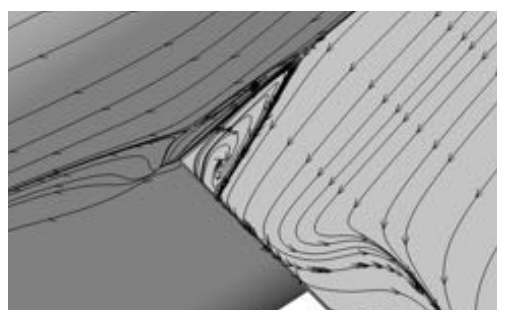

(m) CFD-Air, $\alpha=10.0^{\circ}$

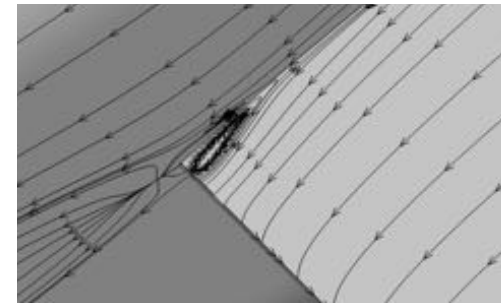

(b) CFD-WT, $\alpha=0.0^{\circ}$

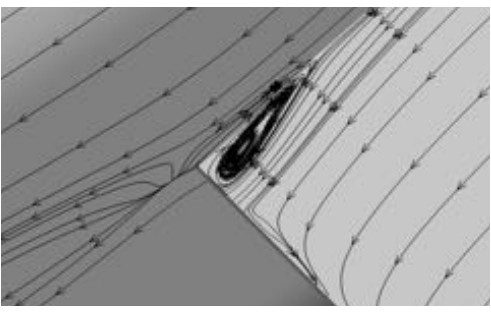

(e) CFD-WT, $\alpha=2.5^{\circ}$

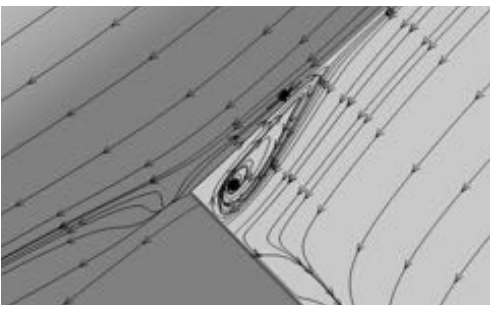

(h) CFD-WT, $\alpha=5.0^{\circ}$

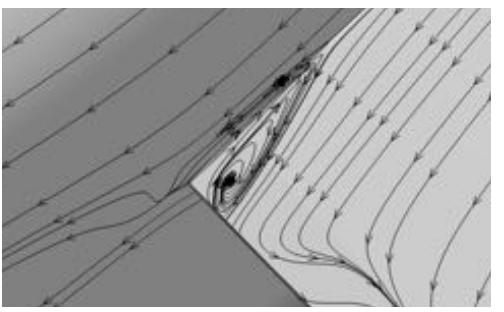

(k) CFD-WT, $\alpha=7.5^{\circ}$

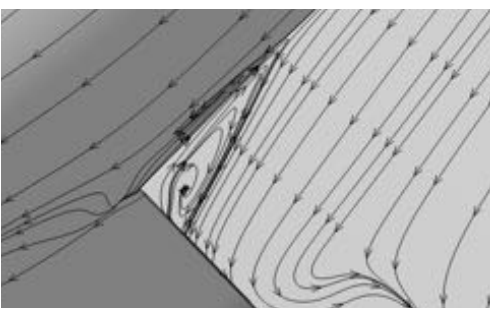

(n) CFD-WT, $\alpha=10.0^{\circ}$

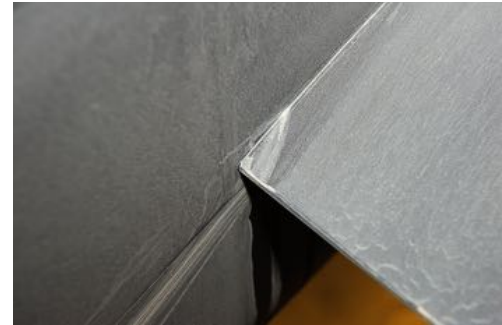

(c) Experiment, $\alpha=0.0^{\circ}$

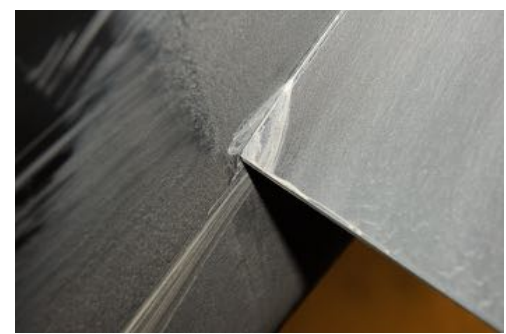

(f) Experiment, $\alpha=2.5^{\circ}$

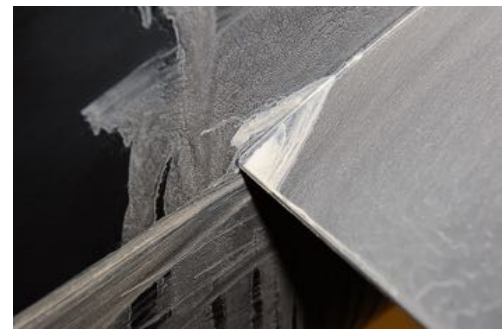

(i) Experiment, $\alpha=5.0^{\circ}$

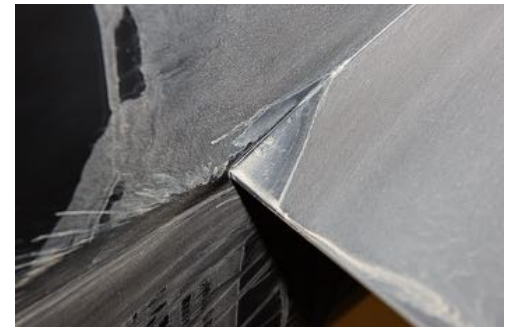

(1) Experiment, $\alpha=7.5^{\circ}$

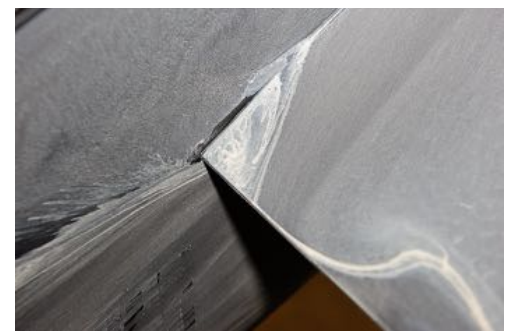

(o) Experiment, $\alpha=10.0^{\circ}$

Figure 28. Side-of-body separation versus model angle of attack, Configuration 2 NACA $0015 \mathrm{mod}$ starboard wing, surface streamlines and oil-flow, $\alpha=0.0^{\circ}$ to $10.0^{\circ}$. 


\section{Configuration 3: F6S12 (port) wing}

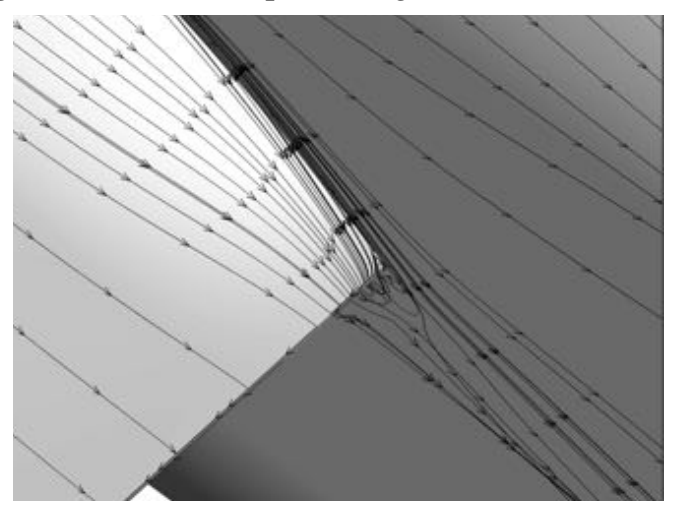

(a) CFD-Air, $\alpha=-10.0^{\circ}$

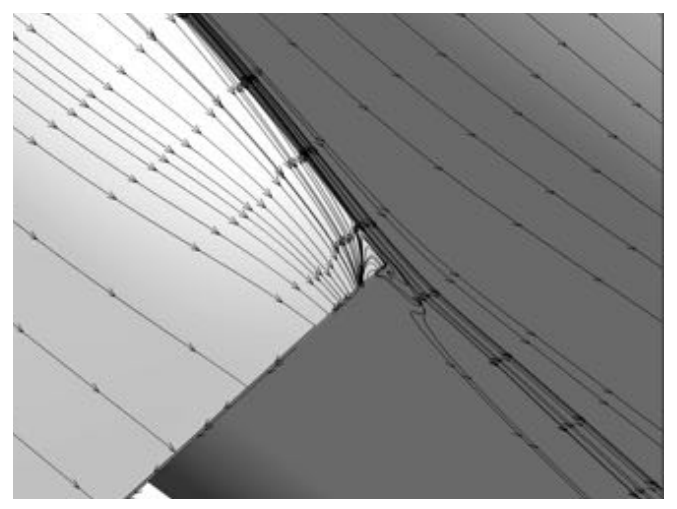

(c) CFD-Air, $\alpha=-5.0^{\circ}$

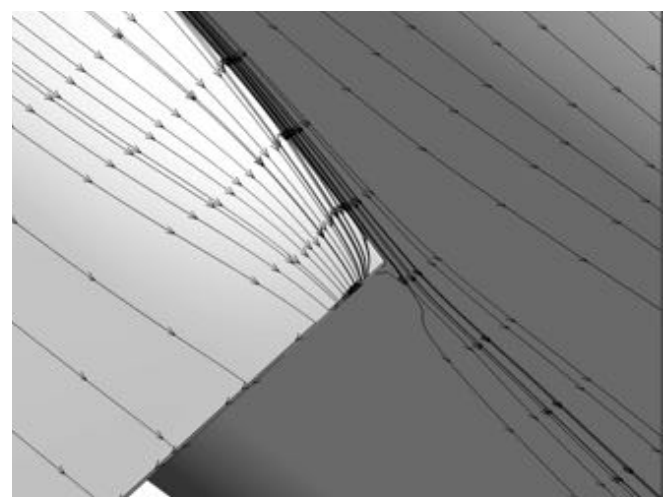

(b) CFD-Air, $\alpha=-7.5^{\circ}$

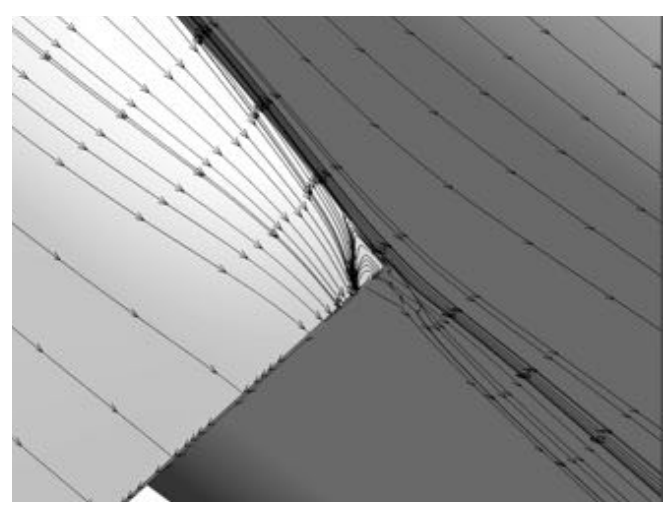

(d) CFD-Air, $\alpha=-2.5^{\circ}$

Figure 29. Side-of-body separation versus model angle of attack, Configuration 3 F6S12 port wing, surface streamlines and oil-flow, $\alpha=$ $-10.0^{\circ}$ to $-2.5^{\circ}$. 


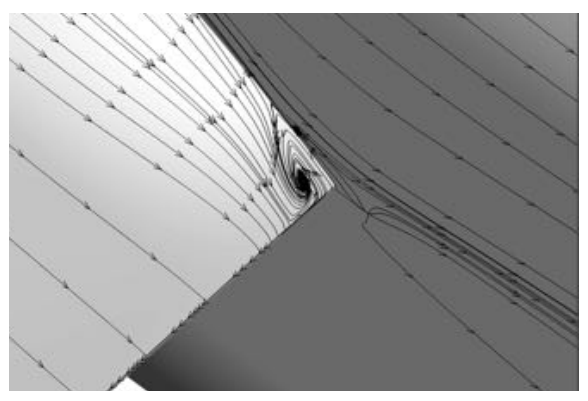

(a) CFD-Air, $\alpha=0.0^{\circ}$

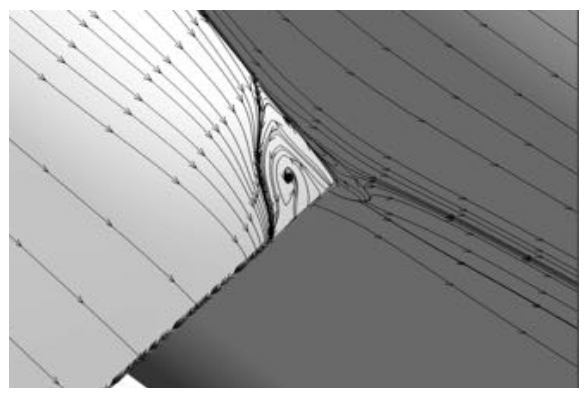

(c) CFD-Air, $\alpha=2.5^{\circ}$

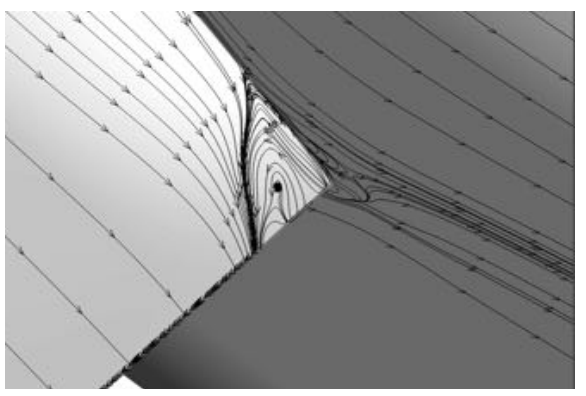

(e) CFD-Air, $\alpha=5.0^{\circ}$

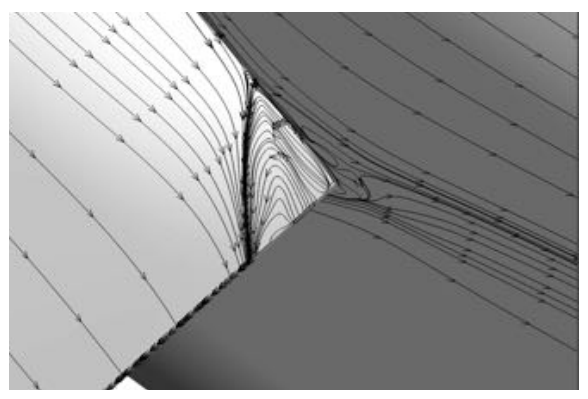

(g) CFD-Air, $\alpha=7.5^{\circ}$

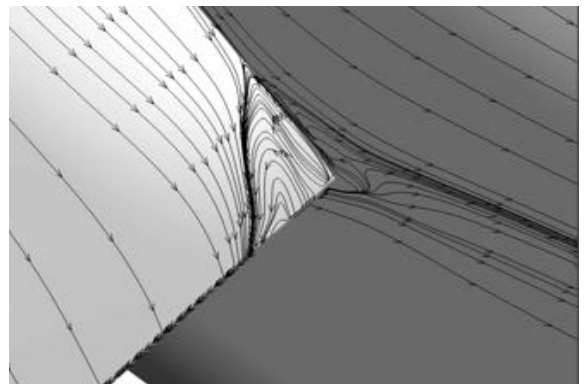

(i) CFD-Air, $\alpha=10.0^{\circ}$

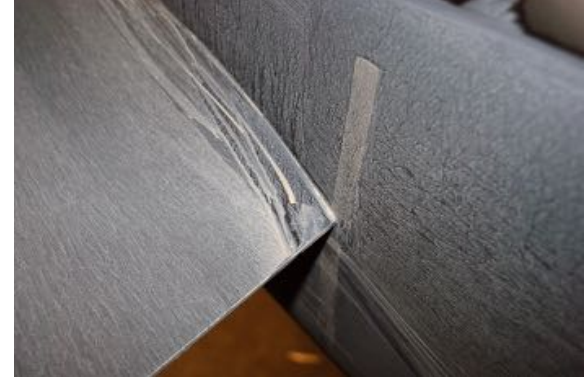

(b) Experiment, $\alpha=0.0^{\circ}$

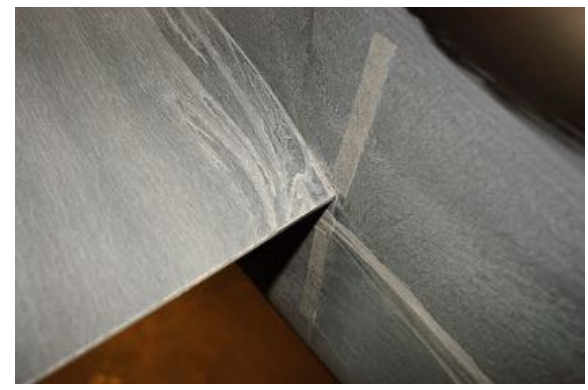

(d) Experiment, $\alpha=2.5^{\circ}$

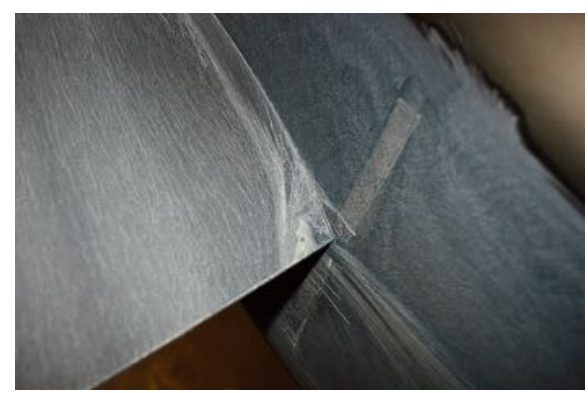

(f) Experiment, $\alpha=5.0^{\circ}$

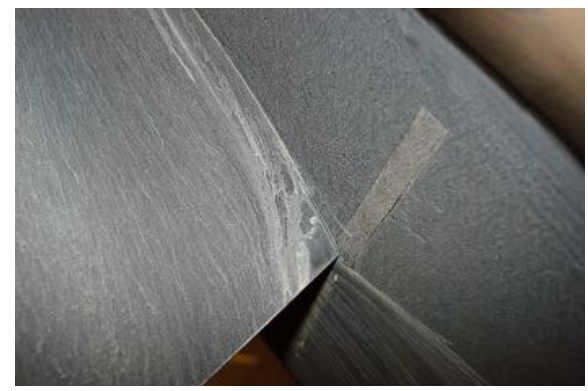

(h) Experiment, $\alpha=7.5^{\circ}$

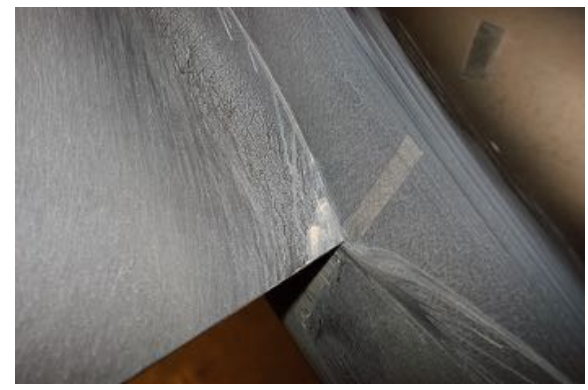

(j) Experiment, $\alpha=10.0^{\circ}$

Figure 30. Side-of-body separation versus model angle of attack, Configuration 3 F6S12 port wing, surface streamlines and oil-flow, $\alpha=$ $0.0^{\circ}$ to $10.0^{\circ}$. 
Configuration 3: COCA (starboard) wing

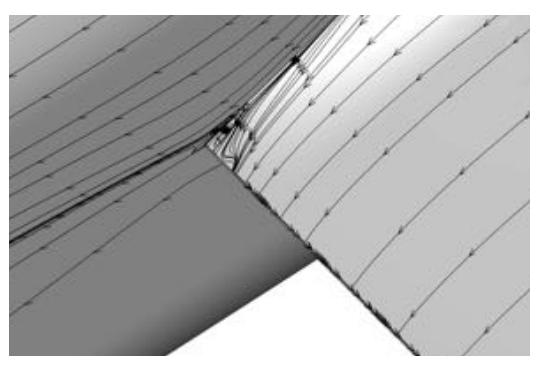

(a) CFD-Air, $\alpha .32=0.0^{\circ}$

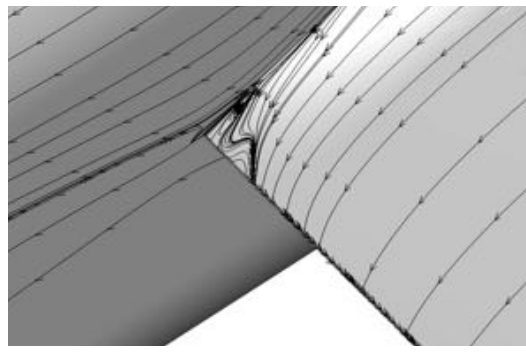

(c) CFD-Air, $\alpha=2.5^{\circ}$

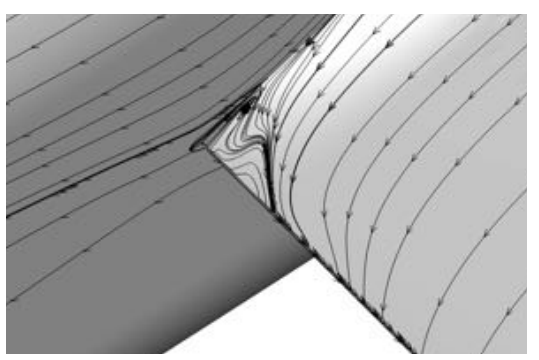

(e) CFD-Air, $\alpha=5.0^{\circ}$

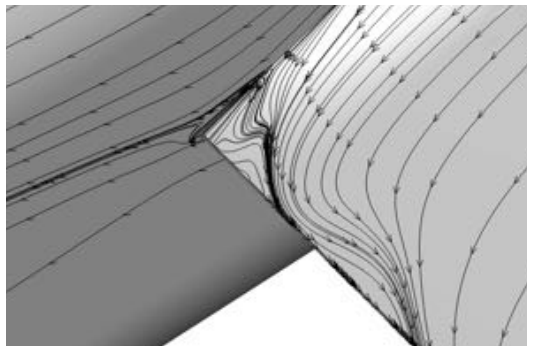

(g) CFD-Air, $\alpha=7.5^{\circ}$

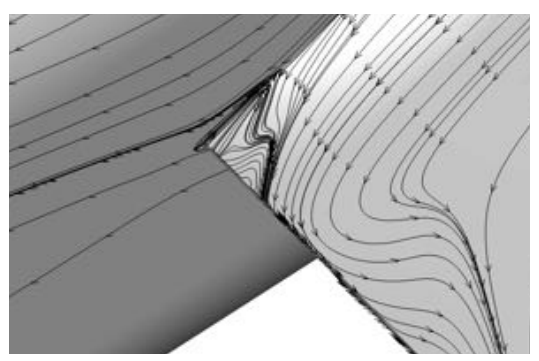

(i) CFD-Air, $\alpha=10.0^{\circ}$

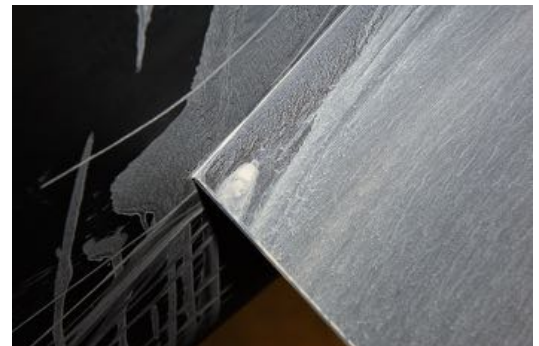

(b) $\alpha=0.0^{\circ}$

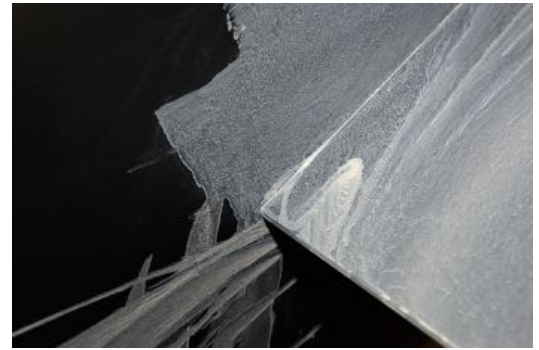

(d) $\alpha=2.5^{\circ}$

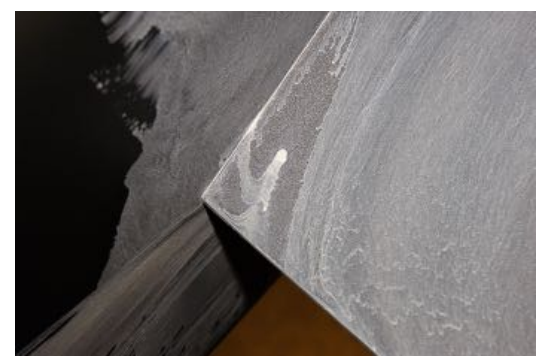

(f) $\alpha=5.0^{\circ}$

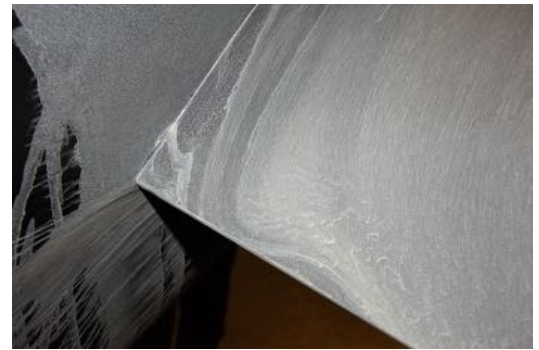

(h) $\alpha=7.5^{\circ}$

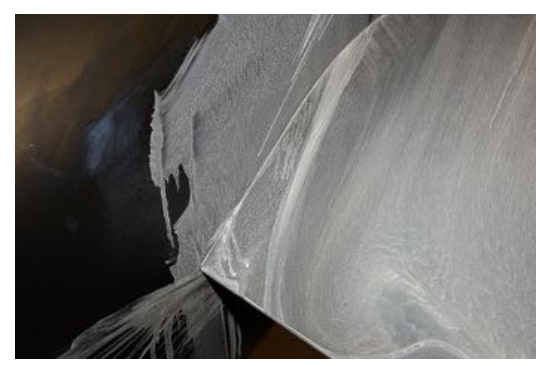

(j) $\alpha=10.0^{\circ}$

Figure 31. Side-of-body separation versus model angle of attack, Configuration 3 COCA starboard wing, surface streamlines and oil-flow. 